NASA Contractor Report 185121

AIAA-89-2413

\title{
The Development of Power Specific Redlines for SSME Safety Monitoring
}

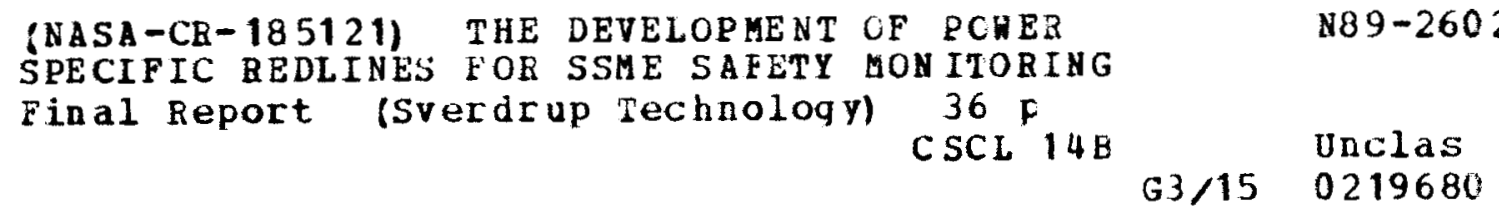

William A. Maul and Claudia M. Bosch

Sverdrup Technology, Inc.

NASA Lewis Research Center Group

Cleveland, Ohio

June 1989

Prepared for

Lewis Research Center

Under Contract NAS3-25266

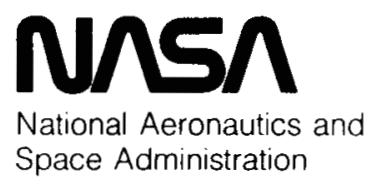

Space Administration 


\title{
The Development of Power Specific Redlines for SSME Safety Monitoring
}

\author{
William A. Maul and Claudia M. Bosch \\ Sverdrup Technology, Inc./NASA Lewis Research Center Group \\ Cleveland, Ohio 44135
}

\begin{abstract}
Over the past several years, there has been an increased awareness in the necessity for rocket engine health monitoring because of the cost and complexity of present and future systems. A current rocket engine system, the Space Shuttle Main Engine (SSME), combines a limited redline system with closed-loop control of the engine's thrust level and mixture ratio. Despite these features, 27 tests of the SSME have resulted in major incidents. In this investigation, an SSME transient morlel was used to examine the effect of variations in high pressure turbopump performance on various engine parameters. Based on analysis of the responses, sereral new parameters are proposed for further investigation as power-level specific redlines.
\end{abstract}

\section{Introduction}

The objective of this effort was to analytically investigate a set of parameters and to select candidates for the development of power-level specific redlines which could indicate Space Shuttle Main Engine (SSME) failure earlier than the current detection system. In recent years, there has been increased activity in the area of rocket engine health monitoring and controls driven by concern over the safety and maintainability of the SSME and future engines. Historically, limits, or redlines, on critical parameters have been used to minimize catastrophic failures of expendable licjuid rocket engines on launch vehicles such as the Atlas and Titan. Although the SSME is reusable and relatively more complex than previous engines, its failure control system employs only basic redlines combined with controller limit logic, redundant sensors and controller voting logic.

Despite this failure control system, several SSME test firings have resulted in complete or partial loss of an engine. Forty-five firings have been classitied as failures, and 27 have had sufficient severity to be labelled as major failures (ref. 1 ). Although this represents a small percentage of the more than 1200 test firings to date, the time and cost impacts have been significant, amounting to several hundred million dollars. Due to the time, cost and safety factors involved in rocket engine operation, many investigations are underway which are attempting to provide improvements to the current state of rocket engine health monitoring systems.

Some efforts have focused on the existing sensor set while others have focused on the development of new sensors. The existing sensors have been used in the 
Arvelopment of a Survey/Arquire Failure Detection (SAFD) algorithm to detect failures during the steady state operation of the SSME (ref. 2-4). When tested using data from a limited number of anomalous test firings, SAFD signaled a shutdown earlier than the redline cutoff. In the area of sensors, specialized bearing and turbine blade monitoring techniques have been developed as part of the SSME Alternate Turbopump Development (ATD) program (ref. 5) and advanced sensors have been implemented on a rocket engine health monitoring laboratory test bed (ref. 6). Sipectrometric techniques have also been developed to monitor the SSME plume as a means of indicating engine failure or degradation (ref. $7-8$ ).

In this study, a transient model of the SSME was used to examine the effect of variations in high pressure turbopump performance on modeled parameters which are also sensor measurements. Based on the analysis of the responses, several new parameters are proposed as promising candidates for power-level specific redlines which, in the event of failure, could result in earlier engine shutdown. The effect of variations in high pressure turbopump performance on system behavior was investigated for two reasons. First, these turbopumps are line replaceable units (LRUs) which exhibit a wide range of acceptahle performance. Second, the test history of the engine and failure analysis reports (ref. 9-11) indicate that the high pressure turhopumps deserve a high priority in SSME health monitoring efforts.

\section{Background}

\section{SSME Description}

The Space Shuttle Main Engine (SSME) is a reusable liquid hydrogen and liquid oxygen fueled rocket engine that supplies thrust through a two stage combustion process. The engine consists of two similar subsystems, each containing a low pressure turbopump, high pressure turbopump and a preburner, as shown in figure 1, which supply the oxidizer and the fuel to the main combustion chamber. In the first stage of the combustion process, each preburner produces a hot fuel-rich gaseous mixture that is used to drive its respective high pressure turbine. The second stage is a controlled burn in the main combustion chamber that produces the engine's thrust.

The SSME components are highly interdependent. 'The low pressure pumps provide the necessary pressure increase between the propellant tanks and the high pressure pumps and are driven by the low pressure turbines. The high pressure fuel pump supplies hydrogen to the various cooling circuits throughout the engine. The heated hydrogen is then used to drive the low pressure fuel turbine and to supply finel to the preburners and to the main combustion chamber. The high pressure oxidizer pump supplies oxidizer to the nain combustion chamber and to the low pressure oxidizer turbopump to drive its turbine. The high pressure oxidizer pump boost stage, or preburner boost pump, is fed by the high pressure oxidizer pump and supplies oxidizer to the preburners. The fuel and oxidizer preburners are used to drive their respective high pressure turbines. Therefore, the performance of each component has at least an indirect effect on the operation of the overall system. 
The control system commences closed-loop control of the main combustion chamber pressure at start +.74 seconds and closed loop control of the mixture ratio at start +3.6 seconds. Thrust control is achieved by using the error between the reference and actual main combustion chamber (MCC) pressures to drive the oxidizer preburner oxidizer valve (OPOV). The fuel preburner oxidizer valve (FPOV) is used to control the main combustion chamber mixture ratio. This control system allows the SSME to be a throttleable rocket engine with an operating range between 6.3 and $111 \%$ of rated power level (RPL). At 100\% RPL, the SSME has a vacuum thrust of $470,000 \mathrm{lbs}$ and a chamber pressure of 3006 psia (ref. 12).

\section{Ciurent Flight Redlined Parameters}

Redlines place performance boundaries upon critical parameters which, when exceeded, result in engine shutdown. The SSME has seven start confirm and five Hight redlined parameters (ref. 13). Experience and engineering judgement have been responsible for the redlined parameters selected, the type and value of the redline limits, and the implemetation of the redlines during flight and ground test firings. Some of these redlines have becn in place since the beginning of SSME testing while others have been established in response to failures. The five flight redlined parameters, all of which monitor the high pressure turbopumps, are summarized in this section.

The high pressure fuel turbine (HPFT) discharge temperature has an upper limit redline set at $1960^{\circ} \mathrm{R}$ and is initiated at start +5.04 seconds. This limit was established to prevent turbine blade stress rupture due to the high temperatures experienced during operation. The limit was based upon the maximum temperature that the blade could withstand at $109 \%$ RPL with a $100^{\circ} \mathrm{R}$ margin of safety.

The High Pressure Oxidizer Turbine (HPOT) discharge temperature, has both an upper limit redline of $1760^{\circ} \mathrm{R}$ and a lower limit redline of $720^{\circ} \mathrm{R}$. The lower limit was set to prevent icing conditions which could cause loss of the preburner oxidizer valve control. The upper redline was assigned to prevent degradation of the heat. exchanger based upon its life capabilities for temperatures up to $1860^{\circ} \mathrm{R}$. Linit. monitoring commences at start +2.3 seconds for the upper limit and at start +3.8 seconds for the lower limit.

The high pressure fuel turbopump (HPFTP) coolant liner pressure has an upper limit redline that varies with the operating power level; thus, it is a powerlevel specific redline. This varying redline was established to prevent buckling of the HPFTP coolant liner which would result in the restriction of the coolant How; linit monitoring begins at start +5.04 seconds. The limit is based upon ground test data and provides a minimum safety margin of $100 \mathrm{psi}$. This power-level specific redline limit is determined by the following linear function of main combustion chamber pressure, $P_{c}$, (ref. 3)

$$
\text { Redline Limit }=A_{0}+A_{1} * P_{c}+\text { Limit Tolerance, }
$$

where the nominal values for the coefficients are $A_{0}=-97.3$ psi and $A_{1}=1.1583$, and the tolerance limit is 451 psi. 
The final two redlined parameters were established to prevent interfacing of the hot gas and liquid oxidizer in the high pressure oxidizer turbopump. A lower limit redline 170 psia was established for the intermediate seal purge pressure to determine excessive seal wear or loss of helium purge pressure. An upper limit of 100 psia was established for the secondary turbine seal pressure to detect seal failure. Both redlines are activated at engine start, and both are based on analytical models of experimental data and maintain a 10 psi safety margin for the worst case operating conditions.

Monitoring of the redlined parameters involves a voting logic procedure among the redundant sensor measurements of a given parameter in order to prevent a premature shutdown due to a failed sensor. Each qualified sensor channel of a redlined parameter is monitored during every data collection cycle to determine if it is within its linits; limit monitoring is suspended if a channel has been disqualified. A sensor which exceeds its limit for three or more consecutive cycles represents a vote for engine shutdown; a consensus of all qualified sensors for a given redlined parameter results in engine shutdown.

\section{SSME Flight and Test Data}

The SSME data files are divided into two separate data types, CADS (Command and Data Simulator) data and facility data. The CADS data set contains up to 128 engine parameters and includes the flight redlined parameters. These parameters are identified by parameter identification (PID) numbers ranging from 1 to 299. The CADS test stand data files have the same parameter set recorded in the flight data files for a given historical time period and all CADS data files, both flight and test, are recorded at a rate of 25 samples per second.

During SSME tests, additional digital data are recorded by the test stand facility systems. This facility data include parameters from both the engine and the facility test stand that test engineers consider necessary for the control and evaluation of the test. These measured parameters are identified by PID numbers ranging from 300 to 1999 . The recording rate for this type of data file varies from 50 to 60 samples per second, depending upon the test stand facility.

Both the CADS and facility data files are available from the various test stand firings. These include the single engine firings at test stands A1, A2 and B1 located at NASA Stennis Space Center (SSC), test stand A.3 located at the Rocketdyne facility in ('anoga Park. California, and the Main Propulsion Test Article (MPTA) cluster firings performed at SSC. The SSME test hed at NASA Narshall Gipare Flight Center (MSF() also produces the two types of data files. Only the ('Al)s data files are available from SSME flights.

\section{SSME Digital Transient Model}

The digital transient model (DTM) which is described in reference 14 simulates the Space Shuttle Main Engine's performance characteristics through start, mainstage control (scheduled throttles) and shutdown. The input describes a nominal engine; source code and input changes are required to adequately simulate off-nominal engine behavior. 
The model is divided into three major subprograms: fuel, oxidizer, and hot gas. The simulation uses the simple Euler time integration scheme; a typical time step is .0002 seconds. The CADS parameters which are currently simulated by the DTM are given in table 1 . Only two flight redlined parameters are simulated by the computer model, the HPOT and HPFT discharge temperatures. In addition, the dynamic response of these temperature sensors is modeled by the DTM.

The DTM has been run on both a VAX 8800 and an Amdahl 5860 to insure that the model did not exhibit machine specific behavior; no significant difference was observed in the results. A startup simulation of 5 seconds requires approximately 9 minutes of C.PU time on the VAX 8800 and 4 minutes of C.PU time on the Amdahl 5860 .

The DTM was obtained through permission of the program office at NASA Marshall Space Flight Center. The model used in this investigation was current as of September, 1988.

\section{Results and Discussion}

\section{Simulation Results}

The DTM contains head and torque multipliers which can be varied to adjust. the turbomachinery efficiencies and thus to simulate changes in high pressure turbopump operation. Calculations were performed using an SSME performance code and engine test data to establish a range for these multipliers which represent one standard deviation from the test data (ref. 15). The ranges are given in table 2 . A low performing HPOTP, for example, is characterized by reduced efficiencies for the oxidizer turbine, oxidizer pump, and preburner boost pump.

Nine turbopump combinations were considered in this study; the cases are described in table 3. For each case, the engine was throttled from $100 \% \mathrm{RPL}$ to $65 \%$ RPL and from $65 \%$ RPL to $104 \%$ RPL; this is typical of an SSME mission profile (see figure 2). The duration of a steady state interval of the simulation was shortened in comparison to the corresponding flight interval in order to conserve computer resources; a given power level was simulated long enough to demonstrate that steady state performance had been achieved.

Although all of the parameters in table 1 were simulated, several were dismissed from further consideration for power-level specific redlines for a variety of reasons. The fuel and oxidizer flowrates, the calculated mixture ratio, and the MC'('injector end pressure are involved in the closed loop control of the engines thrust and mixture ratio and were not considered for further monitoring by power-level specific redlines in this investigation. The simulated MC C coolant discharge temperature and the HPFP inlet temperature exhibited almost no response to either turbopump) efficiency variations or the power level changes; therefore, these parameters were also not considered. Finally, The main fuel valve (MFV), main oxidizer valve (MOV) and coolant control valve $\left(C^{\prime}(V)\right.$ positions are scheduled parameters and are not affected by the varying turbopump efficiencies. The behavior of the 17 remaining parameters is shown in figures $3-19$. 
Several general comments regarding the figures are in order. During nominal performance the engine is restricted to a maximum power level change of $10 \% / \mathrm{sec}$. This is reflected in the 3.5 seconds required for each parameter to transition from its $100 \%$ RPL value to its $65 \%$ RPL value. Likewise, the throttle up to $104 \%$ RPL requires approximately 3.9 seconds. As shown in the figures, the simulated transitions are relatively smooth.

Furthermore, the figures show that variations in the high pressure turbopump efficiency result in shifts of each parameter's performance from its nominal performance. These shifts, with a few exceptions, were consistent throughout the steady-state and transient regions thus allowing the parameter responses to be analyzed qualitatively. A parameter's response above, below or unchanged with respect to its nominal performance in case 1 was assigned the qualitative values $(+),(-)$ or (0), respectively. Two types of qualitative trends can be defined. A direct or an inverse qualitative trend between two parameters indicates that the qualitative values for both parameters change in a similar or opposite manner, respectively. A qualitative summary of cases $2,3,5$ and 6 , where only one high pressure turbopump efficiency was varied from the nominal operating case, is given in table 4 . The other cases were not included in this table because their qualitative trends may be extrapolated from the cases considered. For example, a parameter which exhibits an inverted qualitative trend with respect to changes in the HPOTP efficiency at nominal HPFTP efficiency, also exhibits the same qualitative trend for changes in the HPOTP efficiency at low or high HPFTP efficiency.

The preburner chamber pressures (figures 3 and 4) display an inverse qualitative trend with efficiency changes of both high pressure turbopumps. This demonstrates the engine's inherent ability to stabilize itself from uncontrollable oscillations, due to small changes within the system. Both the fuel and oxidizer preburner chamber pressures are consistent with the behavior of their respective oxidizer control valves; the FPOV and OPOV responses are shown in figures 5 and 6 . As additional oxidizer is supplied to the fuel-rich preburner mixtures, more combustion takes place and the combustion chamber pressure increases. Both oxidizer control valves respond with an inverse qualitative trend to changes in their respective high pressure turbopump efficiencies. The maximum deviations for both valve responses are approximately equal. The FPOV response, however, varies inversely with respect to the HPOTP efficiency while the OPOV position varies directly with respect to the HPFTP efficiency.

Figures $T$ and 8 show that the high pressure turbine discharge temperatures display an inverse gualitative trend with changes in their respective turbopump efficiencies. Since a more efficient turbine is able to extract more mechanical energy from the working fluid, a decrease in discharge temperature is observed. Another factor affecting the turbine discharge temperature is the preburner chamber pressure; since the turbine inlet flows exit from the preburners. 'The maximum deviations from the nominal case are observed for the high-low efficiency combinations.

Figures 9-12 show the behavior of the available low pressure turbopump parameters. Both the low pressure oxidizer turpopump shaft speed and pump discharge 
pressure display a direct qualitative response to the changes in turbopump efficiencies, while inverse qualitative responses are observed for the low pressure fuel turbopump shaft speed and pump discharge pressure. The deviations in the response of the LPOTP parameters are a factor of three smaller than the equivalent LPFT'P parameters; high pressure turbopump performance changes appear to be reflected more by the LPFTP than the LPOTP.

The responses of the HPFTP parameters to changes in turbopump performance are shown in figures 13 and 14 . The shaft speed and pump discharge pressure show inverse qualitative responses to changes in HPFTP and HPOTP efficiencies. Although these trends may appear contradictory, they are consistent with variations in fuel preburner chamber pressure. As the chamber pressure increases, the shaft speed and pump discharge pressure also increase. The HPFTP shaft speed responds more to changes in HPFTP efficiency while the HPFP discharge pressure responses are evenly distributed for the nine test cases.

'The simulated responses of the HPOTP performance parameters are shown in figures 15-17. The HPOP discharge pressure shifts display direct qualitative trends with respect to HPFTP efficiency changes and relatively small inverted qualitative trends for the HPOTP efficiency changes. For the PBP discharge pressure, a direct qualitative trend with efficiency variations for both high pressure turbopumps is observed, while the PBP discharge temperature's qualitative response varies inversely with the HPOTP and directly with HPFTP efficiency changes. The PBP discharge temperature experiences larger variations due to changes in HPOTP than HPFTP performance.

Figures 18 and 19 show the responses of the MCC fuel injector pressure and MC C coolant discharge pressure to the nine turbopump efficiency combinations. Both parameters display inverse qualitative responses to changes in both high pressure turbopump efficiencies. The response of the coolant discharge pressure is directly related to the HPFP discharge pressure since the HPFP supplies the coolant to all of the cooling circuits. The MCC fuel or hot-gas injector pressure is dependent. primarily upon the performance of both preburners.

The operation of the SSME is complex and the interdependency of the various components is extensive. Thus, a complete explanation of the engine's responses cannot be extracted from the plots. The trends displayed by the simulated results are qualitatively consistent with the behavior of the engine.

\section{Parameter Selection}

In order to select new parameters for power-level specific redlines, the sensitivity of those parameters to system changes was examined. The high pressure turbopumps were selected as the system variables for two reasons. First, the high pressure turbopumps are LRI's which exhibit performance variability. Second, the test history of the engine and failure analysis reports indicate that the high pressure t.urbopumps are components which deserve a high priority in SSME health monitoring efforts. Forty-five test firings of the SSME have been classified as failures, 
and 27 have had sufficient severity to be labelled as major failures. Breakdowns by component of the two failure classifications are given in figures 20 and 21 ; the high pressure turbopump assemblies have been responsible for more failures than any other components.

There are two issues regarding the implementation of the power-level specific rerllines. First, the ideal power specific redline would monitor a parameter through transient as well as steady state regions of performance. At scheduled intervals during the power-level transition, the sensor value would be compared to the permissible operating range at that instantaneous power-level. Sensor noise, sensor lag times and difficulties in modeling the transient behavior of the engine are all factors which contribute to the complexity of the problem. As a first step, therefore, this investigation focused on monitoring the steady state behavior of the engine. The objective of this health monitoring effort was to recommend parameters for new power-level specitic redlines. However, since power level specific parameters on facility data would preclude future implementation in flight, it was concluded that the simulated parameters should also be available on CADS data tapes.

Two criteria were established in determining which of the 17 previously selected parameters were mast promising for new power-level specific redlines. The first criterion involves a nor malization which allows comparisons between parameters of different magnitudes and dimensions. The maximum parameter deviation due to the simulated efficiency variations, over a 1.5 second steady state interval at $100 \%$ RPL was calculated for each parameter. This deviation was then compared to the variation of that parameter during a nominal simulated transition from $100 \%$ RPL to $65 \%$ RPL. The ratio of the two parameters should be relatively small for a power specific redline to be feasible. The HPFT discharge temperature, for example, exhibits a larger variation at $100 \%$ RPL than during the transition from $100 \%$ R.PL to $65 \%$ RPL; thus, the current overall redline may be more appropriate than a power-level specific redline for this parameter. This 9 case simulation has demonstrated a possible nominal operation envelope of the SSME for each parameter. A relatively tight envelope would show the parameter's invariance to acceptable conditions for SSME operation. In figure 22, two normalized parameters, one having a tight envelope, parameter $A$, and the other having a wider envelope, parameter B, are presented to visually demonstrate this feature. Table 5 a presents the results of this analysis. Only those parameters having a ratio of 0.5 or less were chosen for further consideration. By establishing the cutoff ratio level at 0.5 , only those parameters with relatively tight operating envelopes were selected. This should allow for more distinct power-level specific redlines to be established, thereby providing a more effective monitoring of these redlines through a transient.

The second criterion involves a noise to signal comparison of the parameters. The sensor noise deviation at $100 \%$ RPL was compared to the variation of the parameter during a simulated nominal transition from $100 \% \mathrm{RPL}$ to $65 \% \mathrm{RPL}$. The maximum sensor deviation was computed from a 30 second segment of a typical SSME test firing at $100 \%$ RPL. A low signal noise relative to the simulated signal range is desired so that the sensor's noise will not force the bandwidth of the power 
specific redline to be too broad. The sensor deviations and ratios are given in table 5 b. Only parameters having a ratio of 0.1 or less were chosen for power-level specific redline candidates.

Application of these two criteria resulted in the selection of nine parameters for further investigation as power-level specific redlines: $P B P$ discharge temperature. MC coolant discharge pressure, MCC fuel injector pressure, HPFP discharge pressure, FPB chamber pressure, HPOP discharge pressure, OPB chamber pressure, PBP discharge pressure, and LPOTP shaft speed. These parameters are feasible as power specific redlines because they demonstrated resistance to the imposed system variations and small signal noise deviations. Of the nine recommended parameters, seven are associated with engine component pressure, one is the LPOTP shaft speed and the ninth is the PBP discharge temperature.

\section{Concluding Remarks}

The focus of this investigation was to develop a list of promising parameters for new power-level specific redlines. Through computer simulations, responses of several parameters to changes in high pressure turbopump efficiency were analyzed and compared. Each parameter's simulated variation and signal deviation at a given power level were normalized so that the characteristics of the various parameters could be compared. The nine selected parameters displayed an invariance to simulated changes in engine performance and a low signal noise relative to the other parameters. These features allow closer and more distinct redlines, which may detect a failure earlier than the current redline system. They also facilitate a possible application of the redlines through the transient regime. The selected parameters include PBP discharge temperature, MC: ( coolant discharge pressure, MC: ( fuel injector pressure, HPFP discharge pressure, FPB chamber pressure, HPOP discharge pressure, $O P B$ chamber pressure, $P B P$ discharge pressure, and $L P O T P$ shaft speed.

The parameters listed above will be further analyzed and tested so that specitic values can be imposed as power-level specific redlines during the steady state operation of the engine. The proposed redlines must then be tested against previous engine firings to establish their ability to detect engine failure earlier than the current detection system without introducing false alarms. The issue of imposing power-level specific redlines during the scheduled transients must also be addressed. Extensive analysis of engine data is required to determine the feasibility of such an endeavor. Implementation of power-level specific redlines during transients will also require a good understanding of the dynamic response of the sensors. 


\section{Ref e r e n c es}

1. Cikanck, H. A., Characteristics of Space Shuttle Main Engine Failures. AIAA Paper 87-1939, June 1987.

2. Norman, A. and Taniguchi, M., Development of an Advanced Failure Detcction Algorithm for the SSME. AIAA Paper 88-3408, July 1988.

3. Taniguchi, M. H., Failure Control Techniques for the SSME, Contract NAS83605, Phase I Final Report. RI/RD86-165, Rockwell International/ Rocketdyne Division, 1986.

4. Taniguchi, M. H., Failure Control Techniques for the SSME, Contract NAS83605, Phase II Final Report. RI/RD87-198, Rockwell International/ Rocketdyne Division, 1987.

5. Gass, F. D.; Alcock, J. F.; and Flickinger, S. A., Space Shuttle Main Engine Alternate Turbopump Development (SSME-ATD) Health Monitoring Program. AIAA 88-341l, July 1988.

6. Nguyen, K. D.; Cole, D. H.; Perry, J.; and Norman, A., An Integrated Laboratory Test Bed for Rocket Engine Health Monitoring Experimentation. AIAA 88-3240, July 1988.

7. Cikanck, H. A.; ct al., Space Shuttle Main Engine Plume Spectral Monitoring Prcliminary Results. AIAA Paper 87-1782, June 1987.

8. Powers, W. T.; ct al., Plume Spectrometry for Liquid Rocket Engine Health Monitoring. In AGARD CPP No. 448, Engine Condition Monitoring Technology and Experience, May 1988.

9. Glover, R. C.; Kelley, B. A.; and Tischer, A. E., Studies and Analyses of the Space Shuttle Main Engine, Contract NASw-3737. BCD-SSME-TR-67-1, Battelle, Columbus Division, April 1987.

10. Failure Modes and Effects Analysis and Critical Items List, Final Report. MMC-ET-SE05-181, Martin Marietta Denver Aerospace, September 1987.

11. Space Shuttle Main Engine Failure Modes and Effects Analysis and Critical ltems List. RSS-8553-11 and RSS-8740-11, Rockwell International/ Rocketdyne Division, July 1988.

12. SSME Orientation (Part A-Engine). Course No. ME-110(A)RIR, Rockwell Intcrnational/Rocketdync Division, August 1988.

13. Roth, P., Computer Program Contract End Item, Flight 4C Configuration, SSME Controller Operational Program, Parts I and II. CP406R0001, Revision F, Rockwell International/ Rocketdyne Division, November 1988.

14. Nguyen, D. G., Specification: Engine Balance and Dynamic Model. RL00001, Rockwell International/Rocketdyne Division. May 1981. 
15. Nelson, R. A., Rocketdyne Division/Rockwell International, private communication, February 1989.

Table 1. CADS Parameters Which Are Simulated by the DTM

\section{CADS / DTM PARAMETERS}

Flowrate

- fuel flowrate

- LOX flowrate

- calculated mixture ratio

Temperature

- HPFT discharge temperature

- HPOT discharge temperature

- preburner boost pump discharge temperature

- MCC coolant discharge temperature

- HPFP inlet temperature (LPFP discharge temperature)

\section{Pressure}

- MCC injector end pressure

- MCC hot gas injector pressure

- MCC coolant discharge pressure

- LPFP discharge pressure (HPFP inlet pressure)

- HPFP discharge pressure

- HPOP inlet pressure (LPOP discharge pressure)

- HPOP discharge pressure

- preburner boost pump discharge pressure

- fuel preburner chamber pressure

- oxidizer preburner chamber pressure

Speed

- LPOTP shaft speed

- LPFTP shaft speed

- HPFP shaft speed

Valve Position

- FPOV actuator position

- OPOV actuator position

- MFV actuator position

- MOV actuator position

- CCV actuator position 
Table 2. Efficiency variation representing one standard deviation from the current DTM values for the High Pressure Turbopump Components

\begin{tabular}{|l|l|}
\hline \multicolumn{1}{|c|}{ Component } & Efficiency Variation \\
\hline High Pressure Fuel Turbine & $-2.2 \%$ to $+2.2 \%$ \\
High Pressure Fuel Pump & $-2.6 \%$ to $+2.7 \%$ \\
High Pressure Oxidizer Turbine & $-2.8 \%$ to $+2.8 \%$ \\
High Pressure Oxidizer Pump & $-1.2 \%$ to $+1.2 \%$ \\
Preburner Pump & $-8.2 \%$ to $+9.0 \%$ \\
\hline
\end{tabular}

Table 3. High pressure turbopump efficiencies for each simulated test case

\begin{tabular}{|l|ll|}
\hline Case & \multicolumn{1}{|c|}{ HPOTP } & \multicolumn{1}{c|}{ HPFTP } \\
\hline 1 & Nominal & Nominal \\
2 & Low Performing & Nominal \\
3 & Nominal & Low Performing \\
4 & Low Performing & Low Performing \\
5 & High Performing & Nominal \\
6 & Nominal & High Performing \\
7 & High Performing & High Performing \\
8 & Low Performing & High Performing \\
9 & High Performing & Low Performing \\
\hline
\end{tabular}


Table 4. Qualitative performance of the DTM simulation

\begin{tabular}{|l|c|c|c|c|}
\hline \multirow{2}{*}{\multicolumn{1}{|c|}{ Parameter }} & \multicolumn{5}{c|}{ Qualitative Response } \\
\cline { 2 - 5 } & Case 6 & Case 3 & Case 5 & Case 2 \\
\hline Engine Fuel Flowrate & 0 & 0 & 0 & 0 \\
Engine Oxidizer Flowrate & 0 & 0 & 0 & 0 \\
LPFTP Shaft Speed & + & - & - & + \\
LPOTP Shaft Speed & + & - & + & - \\
LPFP Discharge Pressure & - & + & - & + \\
LPOP Discharge Pressure & + & - & + & - \\
HPFTP Shaft Speed & - & + & - & + \\
HPFP Discharge Pressure & - & + & - & + \\
HPOP Discharge Pressure & + & - & + & - \\
PBP Discharge Pressure & + & - & + & - \\
PBP Discharge Temperature & + & - & - & + \\
MCC Coolant Discharge Pressure & - & + & - & + \\
FPB Chamber Pressure & - & + & - & + \\
OPB Chamber Pressure & - & + & - & + \\
MCC Injector End Pressure & 0 & 0 & 0 & 0 \\
MCC Fuel Injector Pressure & - & + & - & + \\
HPFT Discharge Temperature & - & + & + & - \\
HPOT Discharge Temperature & + & - & - & + \\
OPOV Position & + & - & - & + \\
FPOV Position & - & + & - & + \\
\hline
\end{tabular}

$(-)$ indicates a qualitative decrease from Case 1 performance

$(+)$ indicates a qualitative increase from Case 1 performance $(0)$ indicates no qualitative change from Case 1 performance 
Table 5a. Parameter response characteristics to simulated conditions

\begin{tabular}{|c|c|c|c|}
\hline Parameter & $\begin{array}{c}\text { Nominal } \\
\text { Range } \\
100 \% \Rightarrow 65 \% \\
\Delta \mathrm{P}_{\text {nom }}\end{array}$ & $\begin{array}{c}\text { Maximum } \\
\text { Deviation } \\
@ 100 \% \\
\Delta P_{\odot 100 \%}\end{array}$ & $\frac{\Delta \mathrm{P}_{0100 \%}}{\Delta \mathrm{P}_{\text {nom }}}$ \\
\hline HPOP Discharge Pressure & 1665.11 & 17.58 & 0.0106 \\
\hline MCC Fuel Injector Pressure & 1149.82 & 19.68 & 0.0171 \\
\hline LPOTP Shaft Speed & 1076.72 & 19.88 & 0.0185 \\
\hline MCC Coolant Discharge Pressure & 1662.03 & 65.89 & 0.0396 \\
\hline HPFP Discharge Pressure & 2283.06 & 126.73 & 0.0555 \\
\hline LPOP Discharge Pressure & 80.66 & 4.95 & 0.0613 \\
\hline FPB Chamber Pressure & 2012.03 & 133.79 & 0.0665 \\
\hline OPB Chamber Pressure & 2094.18 & 164.12 & 0.0784 \\
\hline HPFTP Shaft Speed & 7536.17 & 602.40 & 0.0799 \\
\hline LPFTP Shaft Speed & 2217.28 & 253.80 & 0.1145 \\
\hline PBP Discharge Pressure & 2933.16 & 409.12 & 0.1395 \\
\hline LPFP Discharge Pressure & 55.83 & 10.59 & 0.1897 \\
\hline PBP Discharge Temperature & 16.29 & 6.82 & 0.4189 \\
\hline FPOV Position & 8.92 & 6.84 & 0.7667 \\
\hline OPOV Position & 9.74 & 8.82 & 0.9051 \\
\hline HPOT Discharge Temperature & 303.35 & 351.60 & 1.1591 \\
\hline HPFT Discharge Temperature & 156.93 & 191.83 & 1.2224 \\
\hline
\end{tabular}

Table 5b. Parameter signal noise compared to transition response

\begin{tabular}{|c|c|c|c|}
\hline Parameter & $\begin{array}{c}\text { Nominal } \\
\text { Range } \\
100 \% \Rightarrow 65 \% \\
\Delta \mathrm{P}_{\text {nom }}\end{array}$ & $\begin{array}{c}\text { Signal } \\
\text { Noise } \\
@ 100 \% \\
\Delta S_{0100 \%}\end{array}$ & $\frac{\Delta S_{\text {o100\% }}}{\Delta P_{\text {nom }}}$ \\
\hline PBP Discharge Temperature & 16.29 & 0.058 & 0.0036 \\
\hline MCC Coolant Discharge Pressure & 1662.03 & 44.57 & 0.0268 \\
\hline MCC Fuel Injector Pressure & 1149.82 & 38.18 & 0.0332 \\
\hline HPFP Discharge Pressure & 2283.06 & 80.49 & 0.0353 \\
\hline FPB Chamber Pressure & 2012.03 & 74.79 & 0.0370 \\
\hline HPOP Discharge Pressure & 1665.11 & 74.22 & 0.0400 \\
\hline OPB Chamber Pressure & 2094.18 & 89.25 & 0.0430 \\
\hline PBP Discharge Pressure & 2933.16 & 121.48 & 0.0550 \\
\hline LPOTP Shaft Speed & 1076.72 & 80.98 & 0.0750 \\
\hline LPOP Discharge Pressure & 80.66 & 10.26 & 0.1300 \\
\hline LPFTP Shaft Speed & 2217.28 & 387.60 & 0.1700 \\
\hline LPFP Discharge Pressure & 55.83 & 8.27 & 0.2260 \\
\hline HPFTP Shaft Speed & 7536.17 & 2463.40 & 0.3300 \\
\hline
\end{tabular}




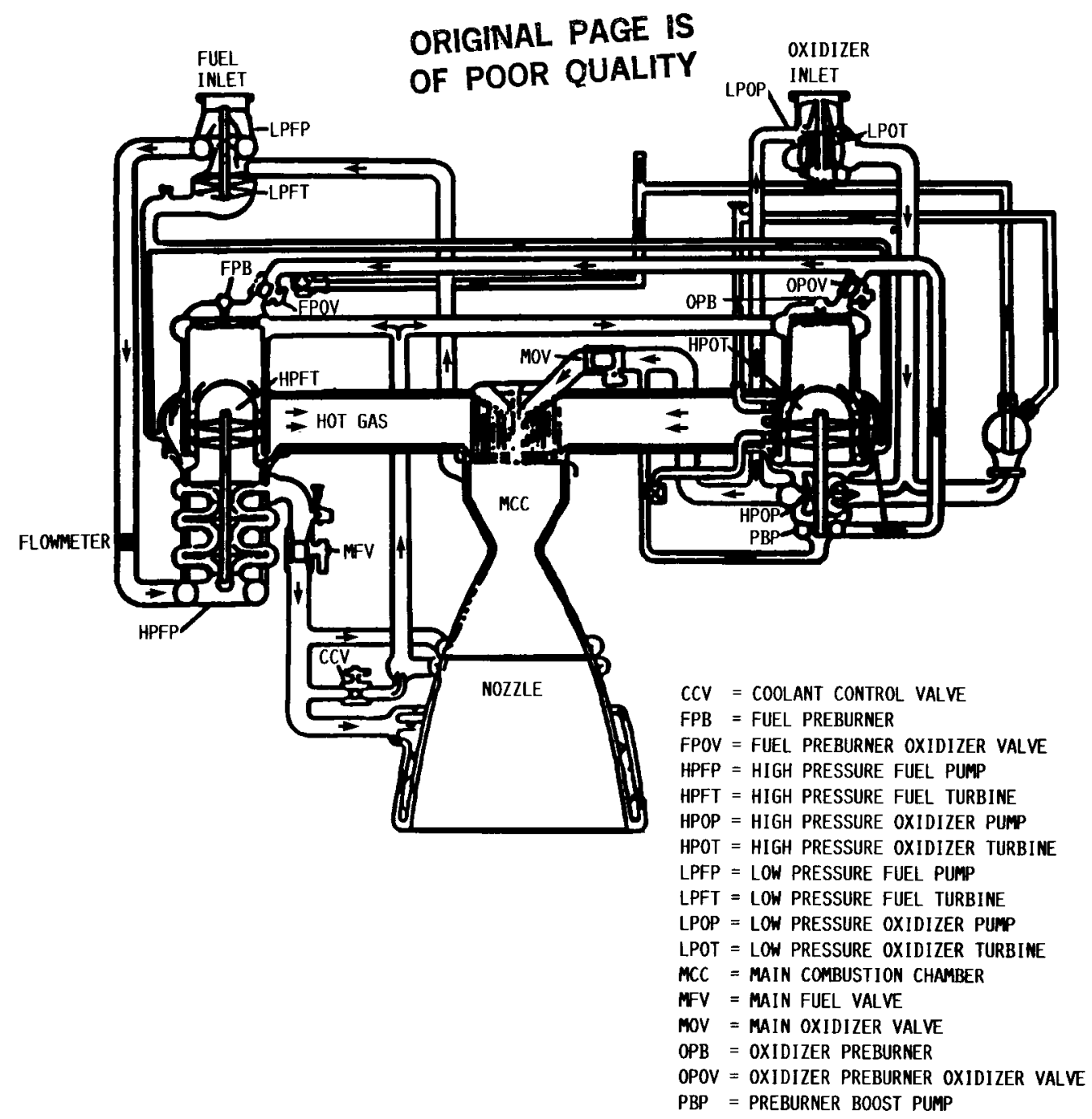

Figure 1. - Space Shuttle Main Engine Schematic.

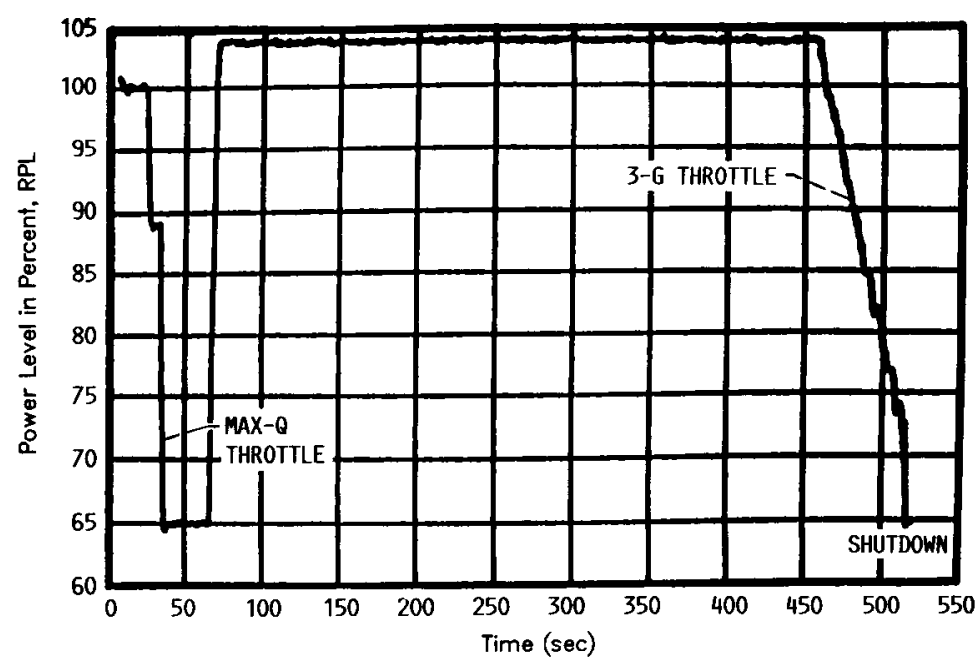

Figure 2. - Typical Space Shuttle Main Engine 104\% Mission. 

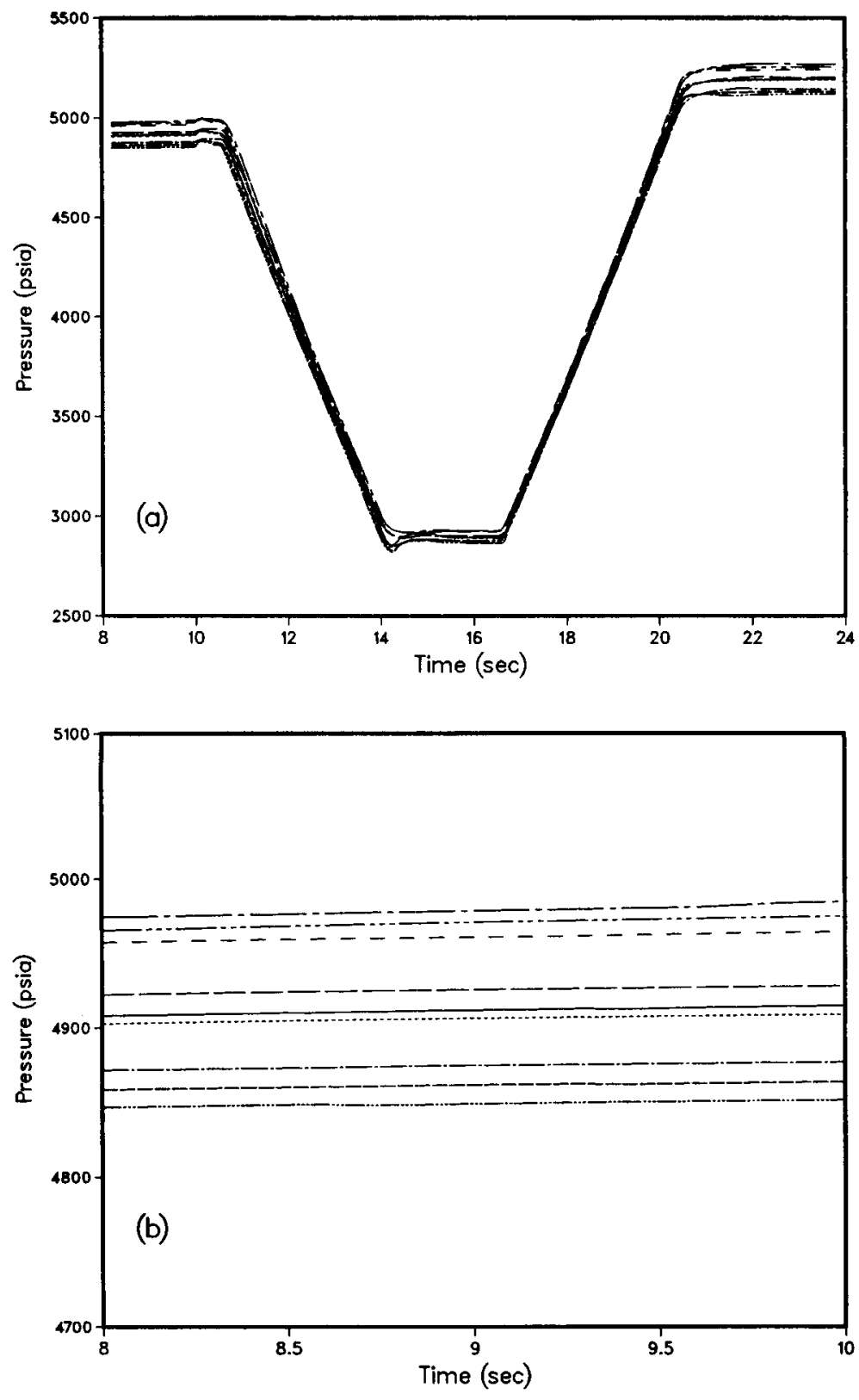

Cose 1

$\operatorname{Cose} 2$

Cose 3

Case 4 -

Cose 5

Cogen 6

Cose 7

Cos: 8

Cosen $-2-$

Figure 3. Fuel preburner chamber pressure response (a). for the entire simulation and (b). at 100\% RPL. 

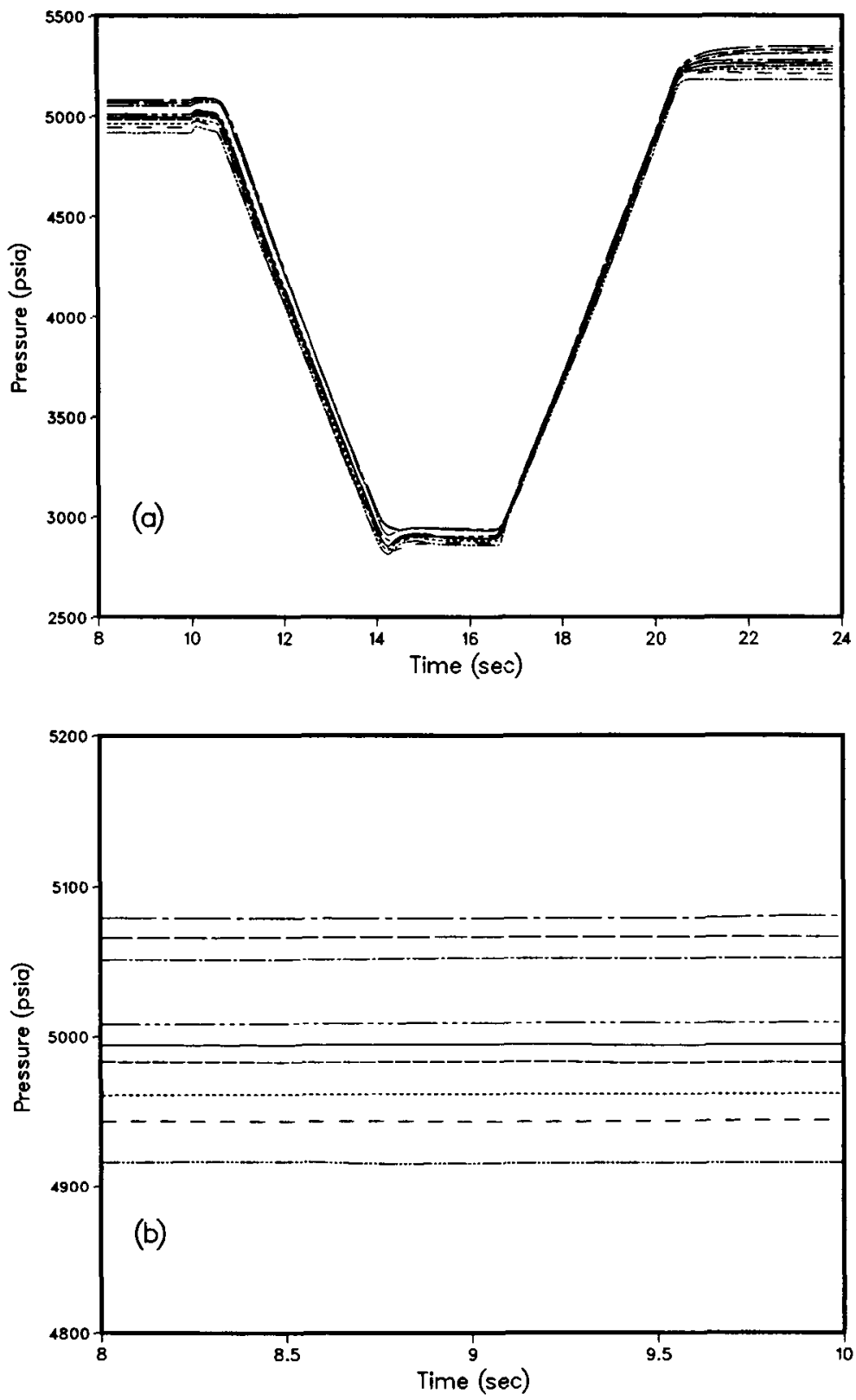

Case 1

Cose 2

Cose 3.

Cose 4

Cose 5 .......................

Cose 6

Cose 7 .........

Cose 8 . - -

Coseg - -

Figure 4. Oxidizer preburner chamber pressure response (a). for the entire simulation and (b). at $100 \%$ RPL. 

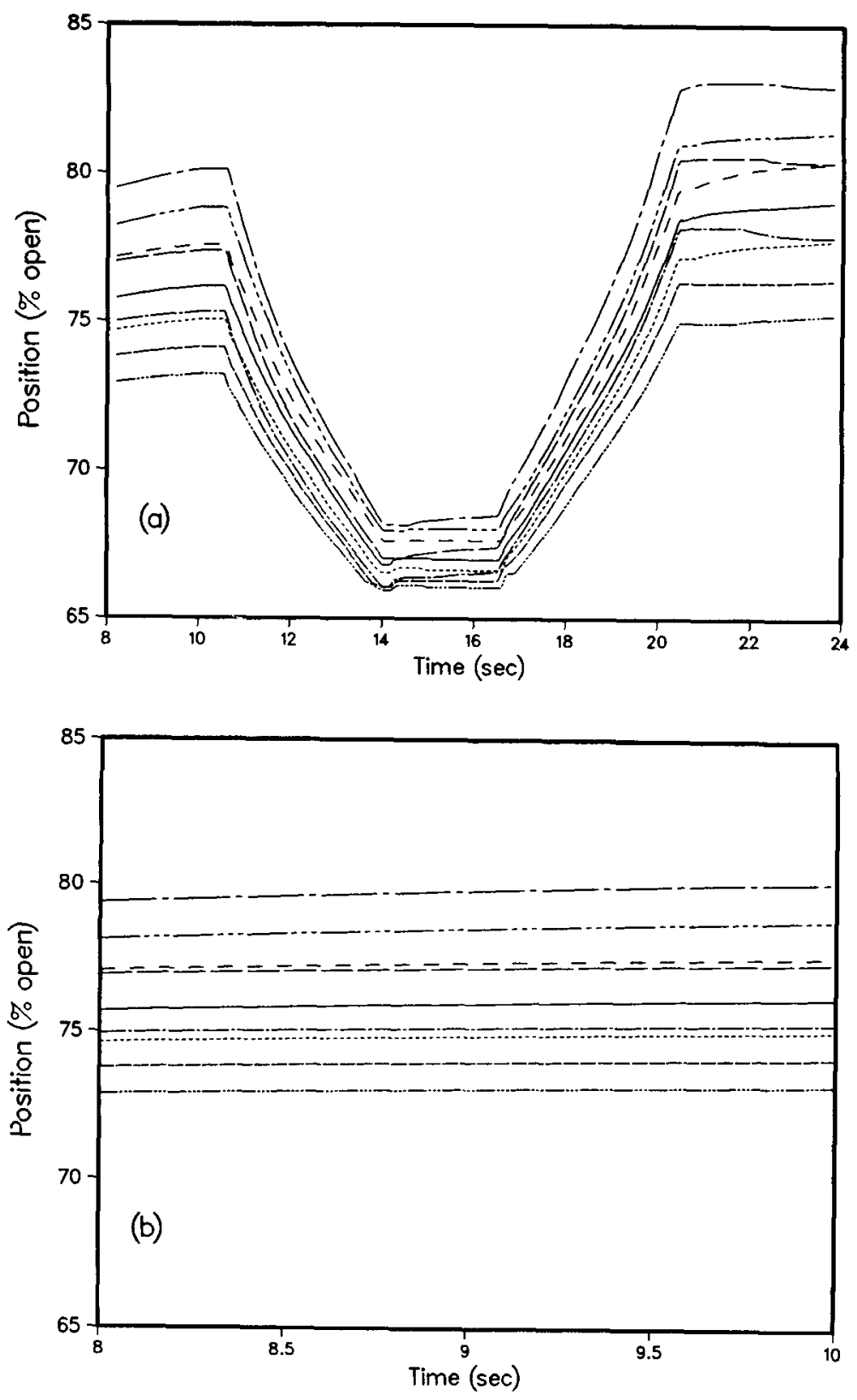

Case

Cose 2

Case 3.

Cose

Cose

Case 6

Cose 7

Cose 8

Coso. - - -

Figure 5. Fuel preburner oxidizer valve position response (a). for the entire simulation and (b). at $100 \%$ RPL. 

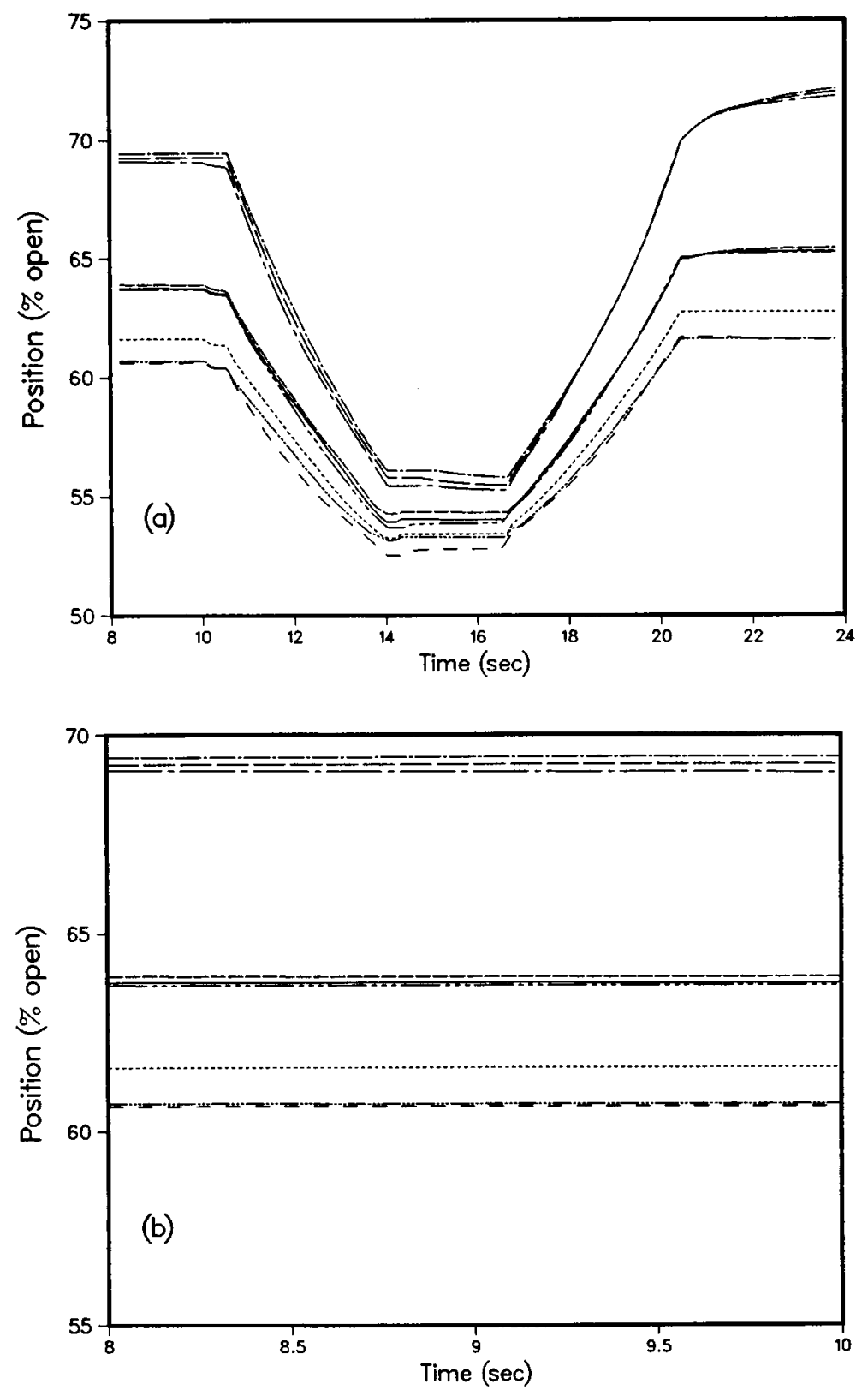

Case 1

Cose 2

Cose $3 . .$.

Cose 4

Coses 5 .

Cose

Cose 7

Cose 8

Coseg - -

Figure 6. Oxidizer preburner oxidizer valve position response (a). for the entire simulation and (b). at $100 \%$ RPL. 

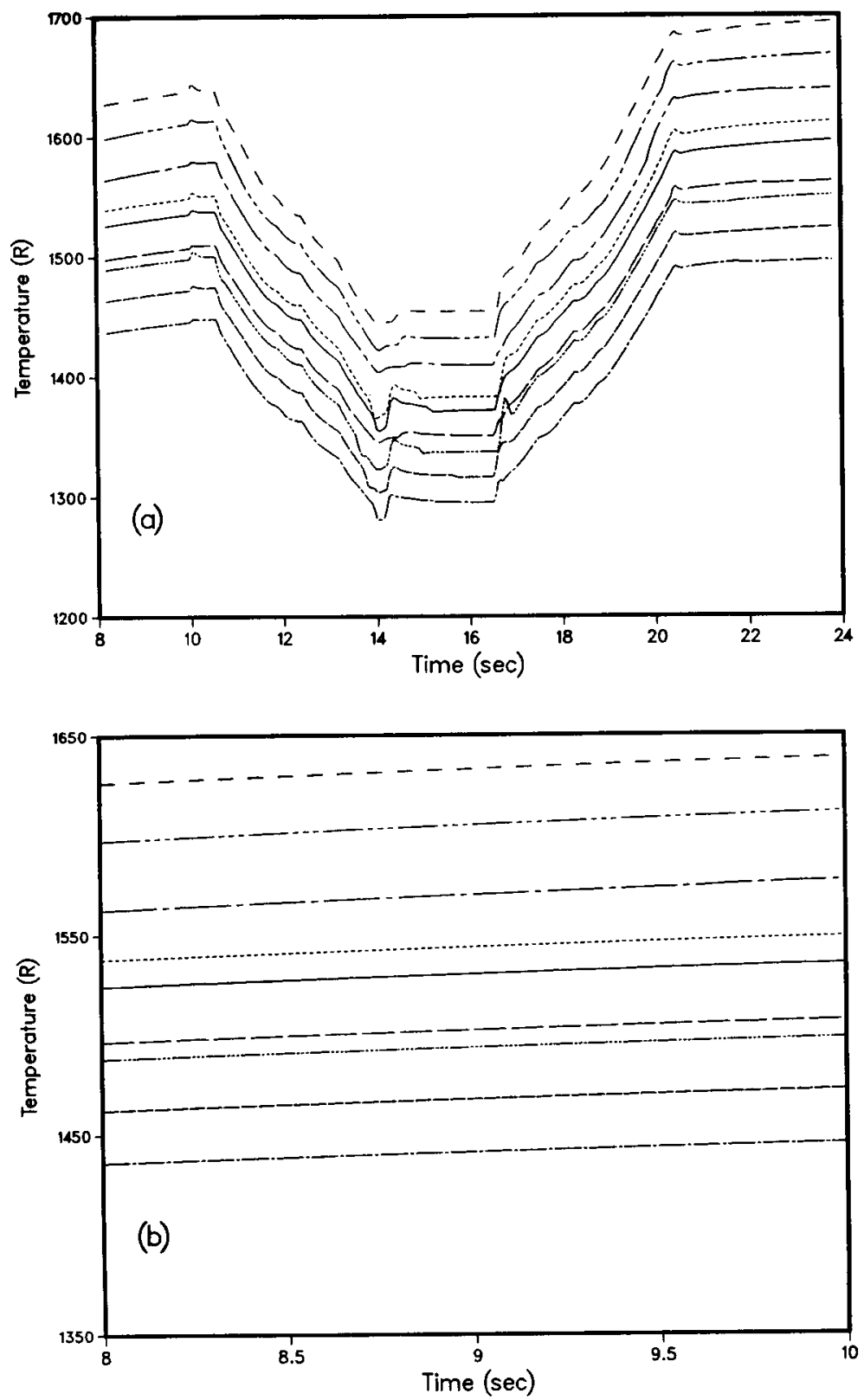

Cose 1

Cose 2

Cose $3 .$.

Cose $4-$

Cose 5

Cose 6

Cose 7

Cose 8 .

Coseg $-\ldots$

Figure 7. HPFT discharge temperature response (a). for the entire simulation and (b). at $100 \%$ RPL. 

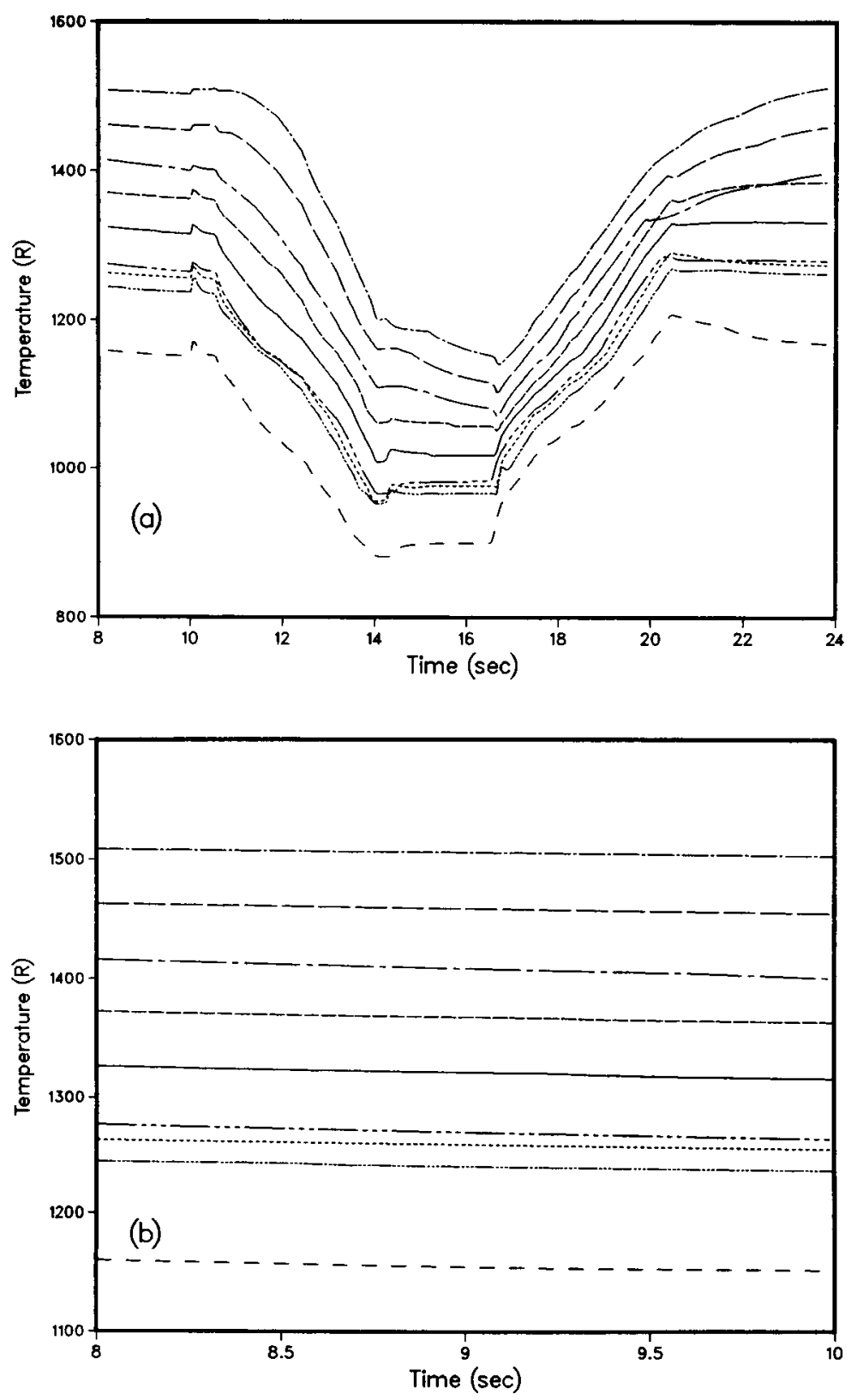

Cose

Cose 2

Cose $3 . .$.

Cose 4

Cose 5 ..............

Cose 6

Cose

Cose 8

Coseg --1

Figure 8. HPOT discharge temperature response (a). for the entire simulation and (b). at 100\% RPL. 

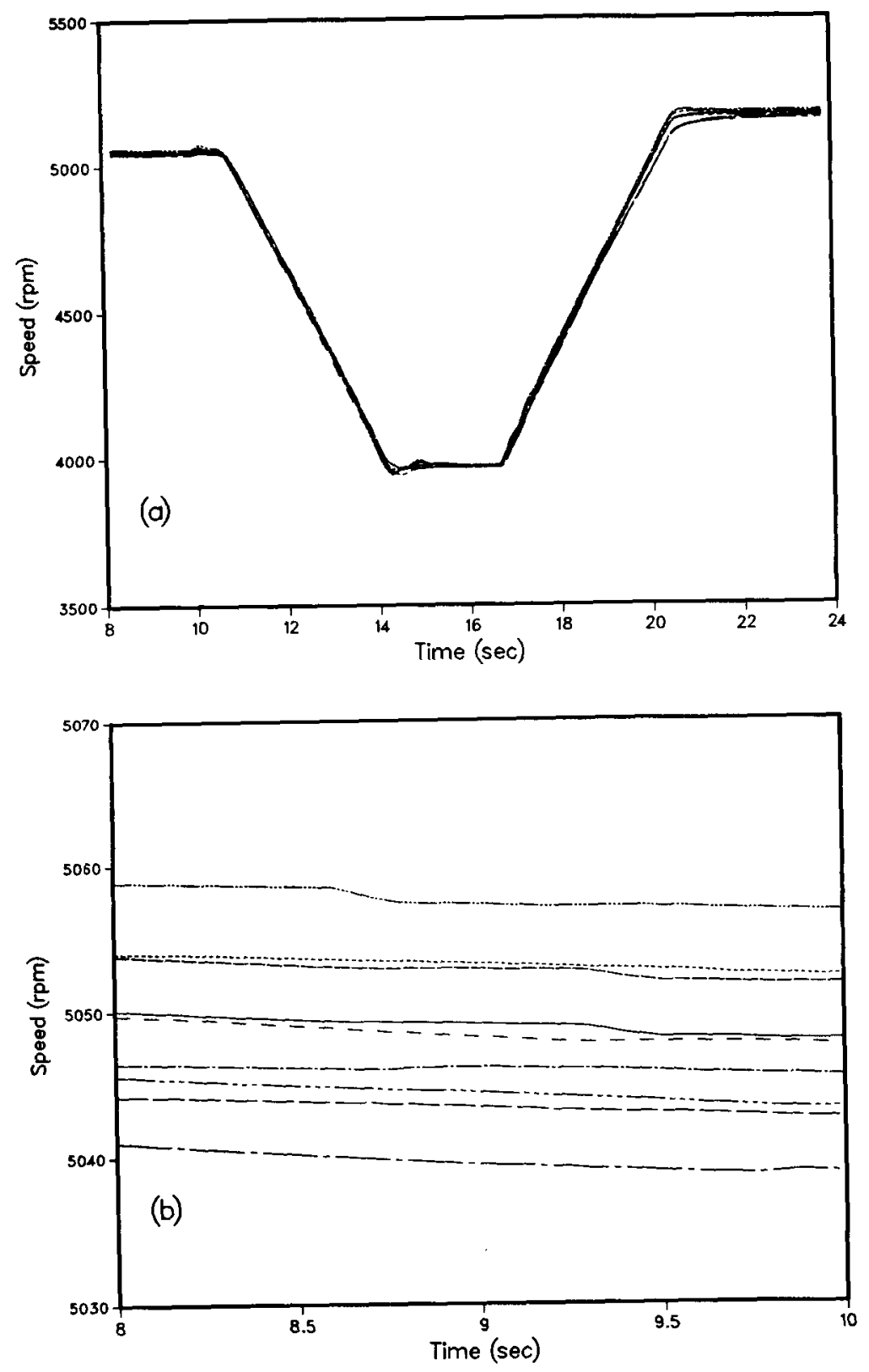

Cose 1

Cose 2

Cose 3

Cose 4 - -

Cose 5

Coge日 6 - --

Cose? 7

Cose 8

Coseg - - -

Figure 9. LPOTP shaft speed response (a). for the entire simulation and (b). at $100 \%$ RPL. 

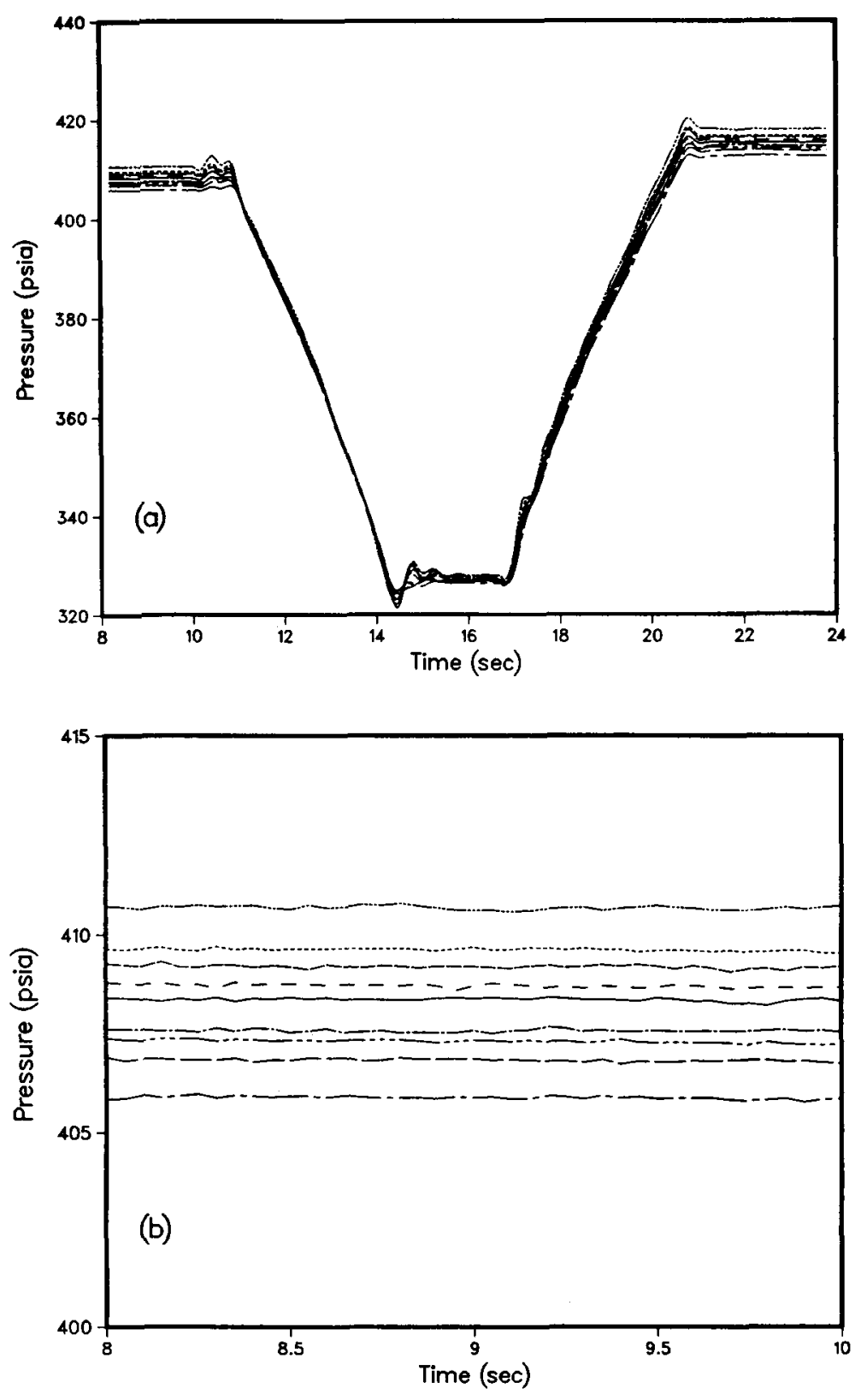

Cose 1

Cose $3 . .-$

Case 4

Coses 5

Coser

Cose 7

Coses.

Cose 9 - -

Figure 10. LPOP discharge pressure response (d). for the entire simulation and (b). at $100 \% \mathrm{RPL}$. 

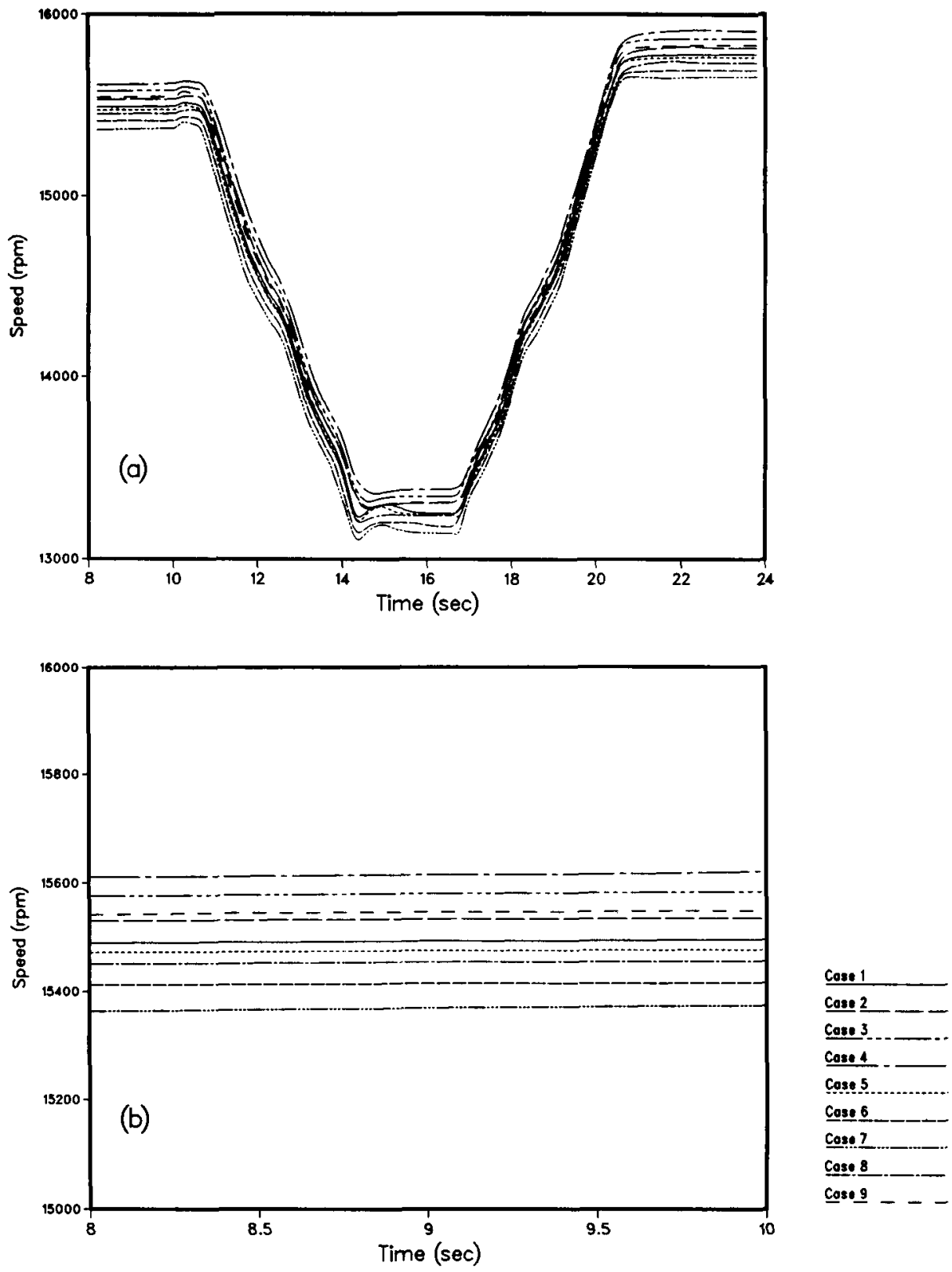

Figure 11. LPFTP shaft speed response (a). for the entire simulation and (b). at $100 \%$ RPL. 

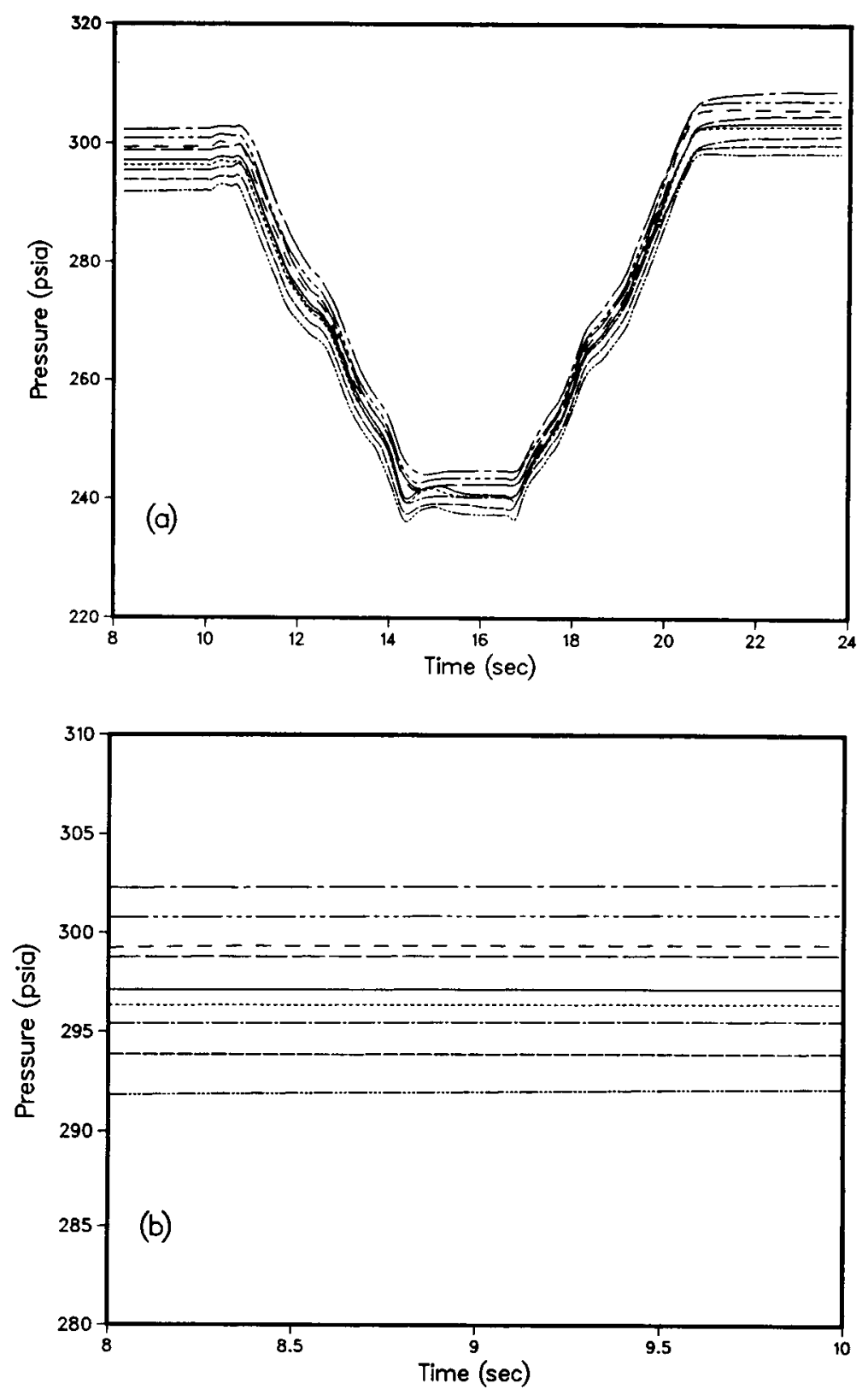

Cose 1

Cose 2

Cose 3

Cose 4 -

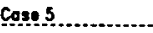

Cose 6

Cose 7

Coses

Coseg --

Figure 12. LPFP discharge pressure response (a). for the entire simulation and (b). at $100 \%$ RPL. 

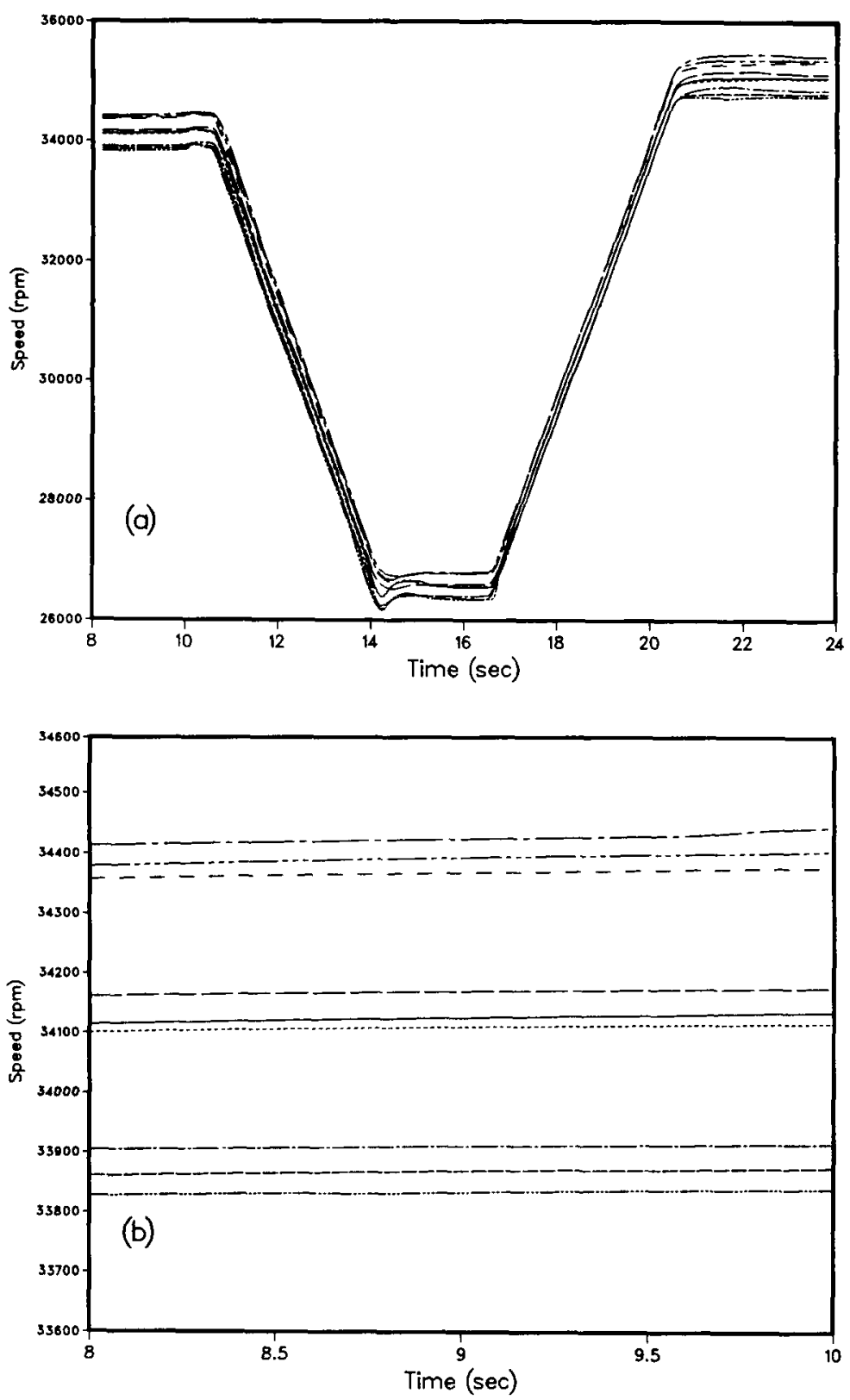

Cose 2

Cose 3

Cose 4

Case 5

Cose 6

$-$

Cose 7

Cose 8

Cosis $9-1$

Figure 13. HPFTP shaft speed response (a). for the entire simulation and (b). at $100 \% \mathrm{RPL}$. 

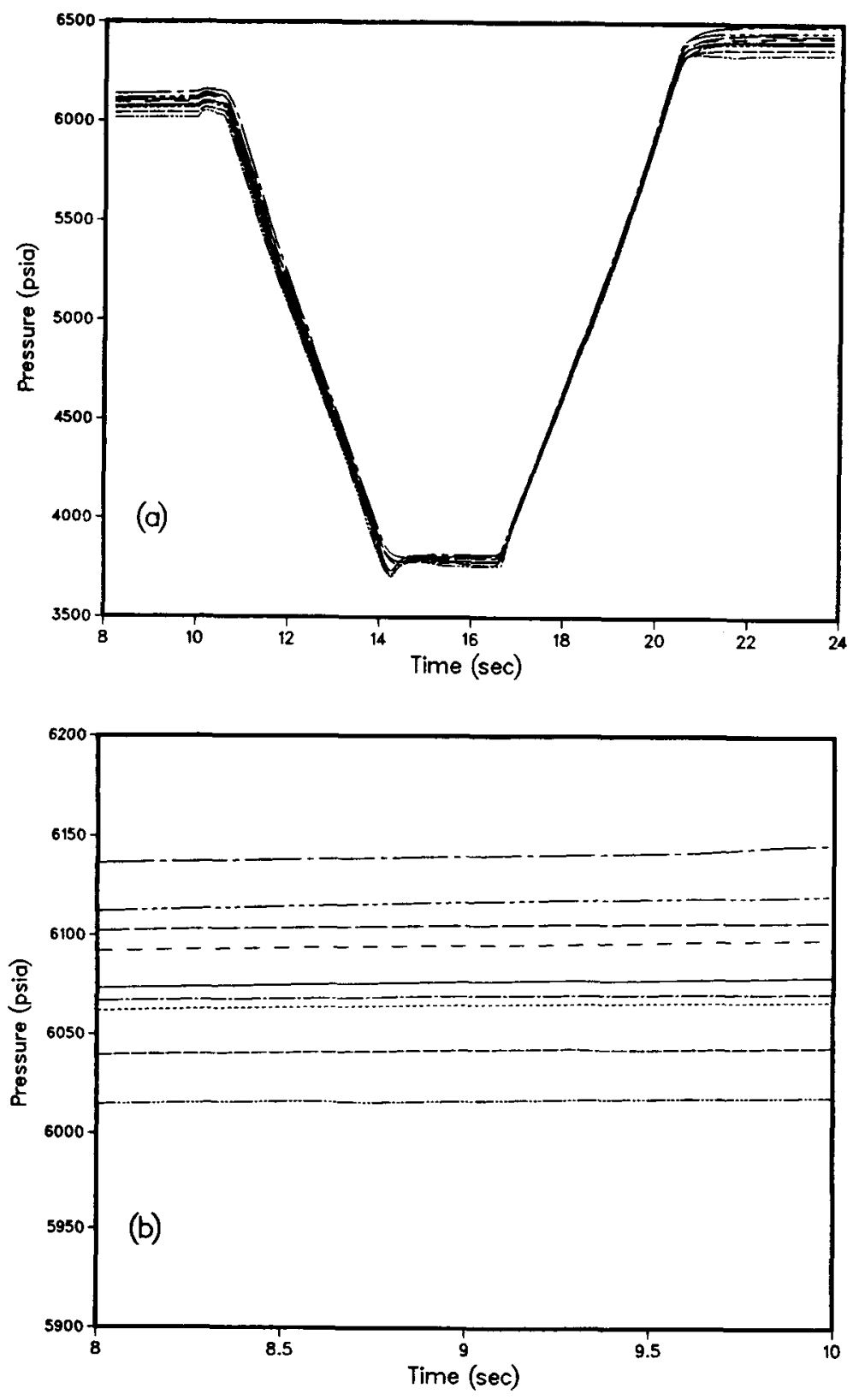

Cose 1

$\operatorname{cose} 2$

Case 3.

Cose 4

Cose 5 .............

Cose 6

Cose 7

Coses

Coseg - -

Figure 14. HPFP discharge pressure response (a.) for the entire simulation and (b). at $100 \%$ RPL. 

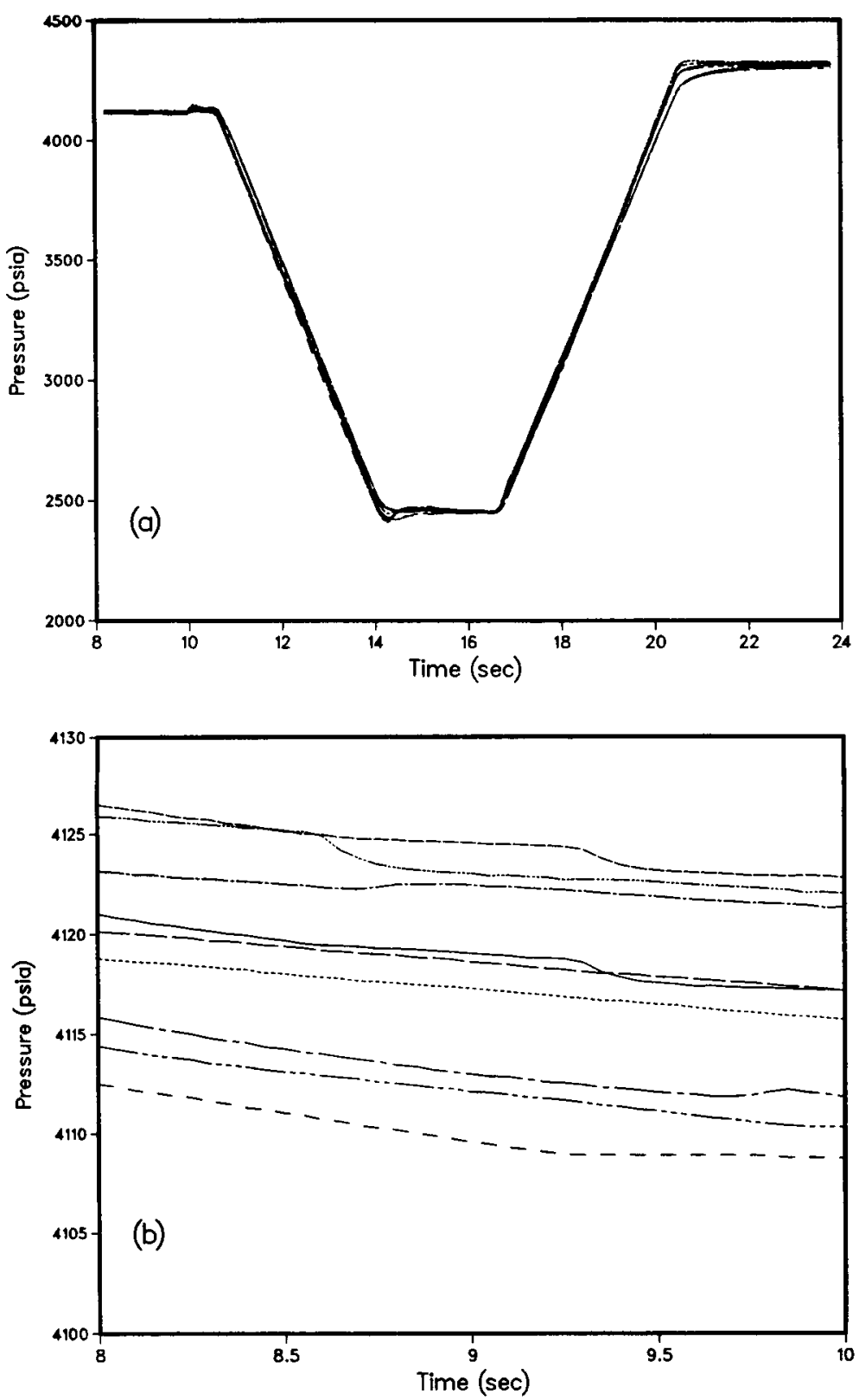

Cose 1

Cose 2

Cose 3.

Cose 4

Cose 5

Coses

Cose?

Coses 8

Cose 9 - -

Figure 15. HPOP discharge pressure response (a). for the entire simulation and (b). at $100 \% \mathrm{RPL}$. 

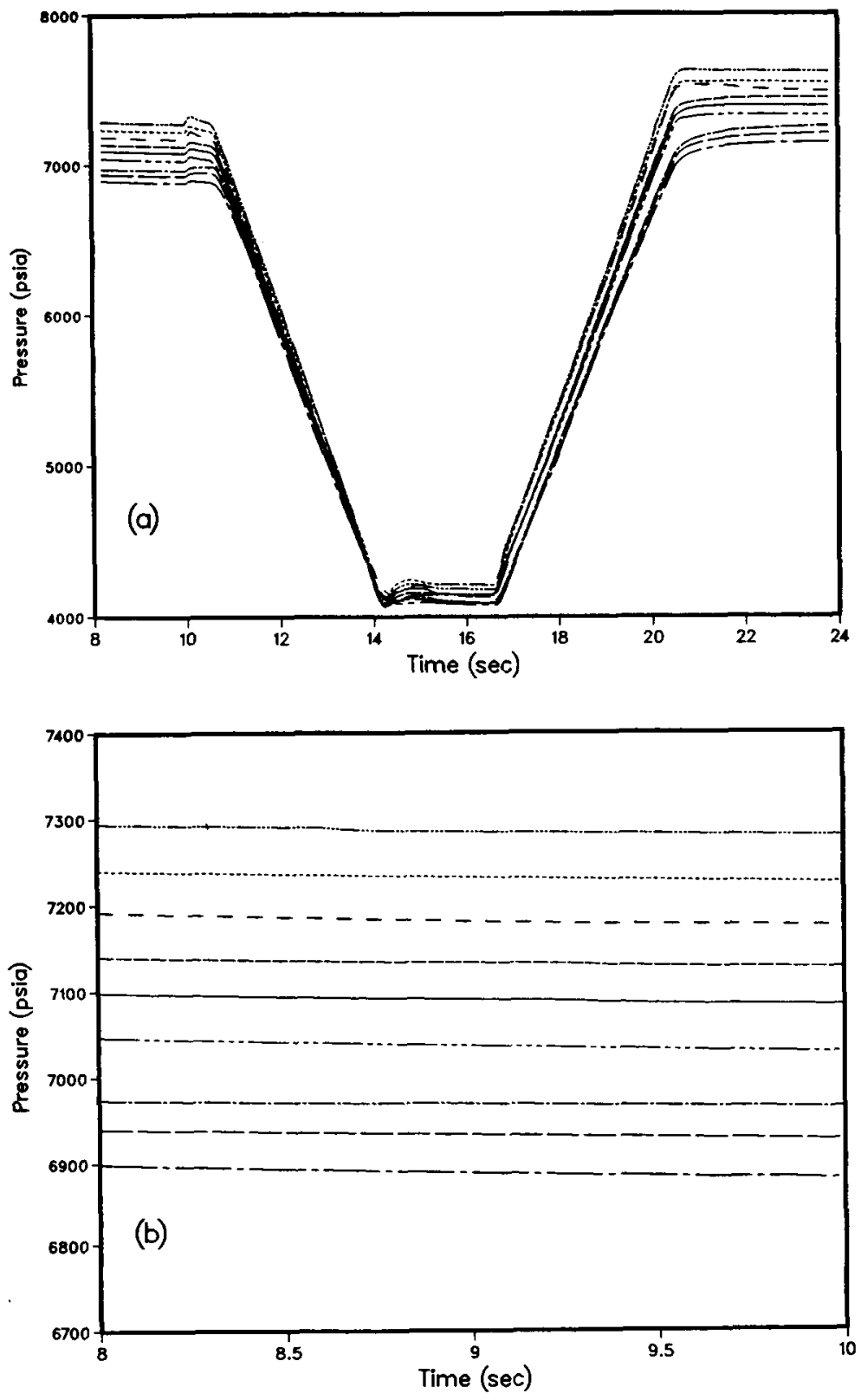

Cose 1

Cose 2

Cose 3.

Cose 4 -

Cos: 5

Conse 6

Cos: 7

Cose 8 - -

Coseg - - -

Figure 16. Preburner boost pump discharge pressure response (a). for the entire simulation and (b). at $100 \%$ RPL. 

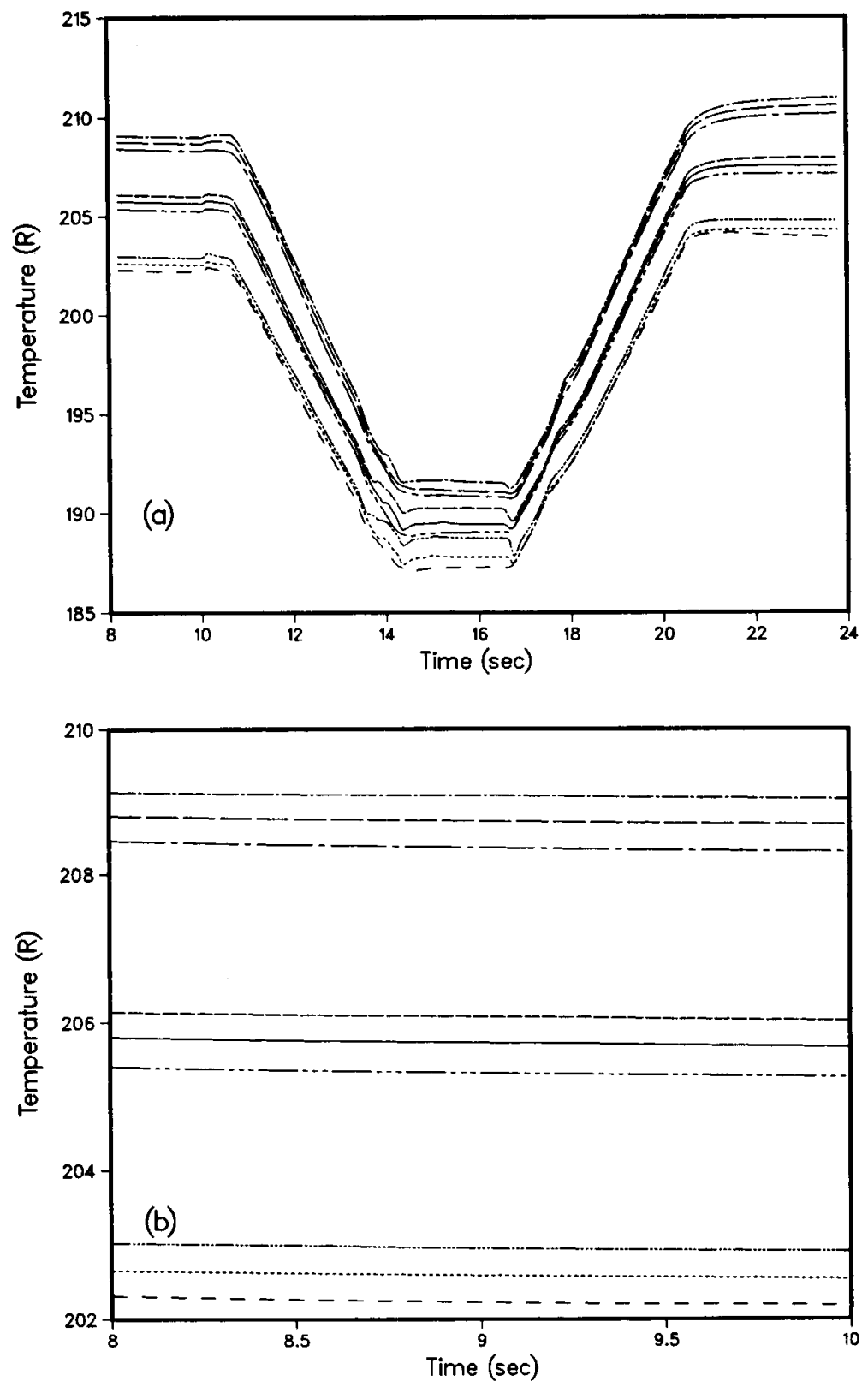

Cose 1

Cose 2

Case 3.

Cose 4

Cose 5

Cose 6

Cose?

Cose 8

Coseg --

Figure 17. Preburner boost pump discharge temperature response (a). for the entire simulation and (b). at $100 \%$ RPL. 

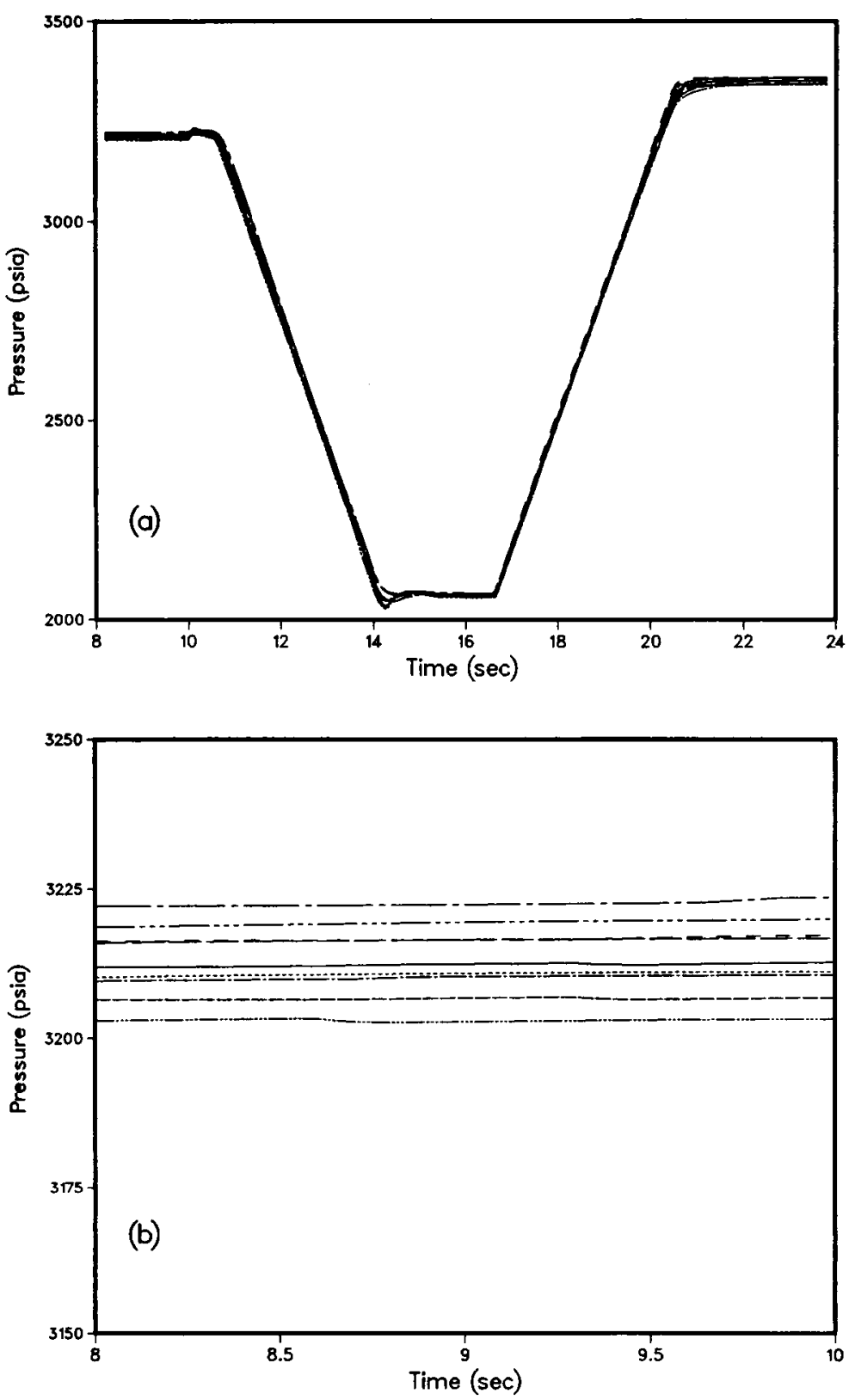

Cose Cose 2 Cose 3

Cose 4

Cose 5

Cose 6

$\operatorname{Cos} 7$

Cose 8 . - -

Coseg - -

Figure 18. MCC fuel injector pressure response (a). for the entire simulation and (b). at $100 \%$ RPL. 

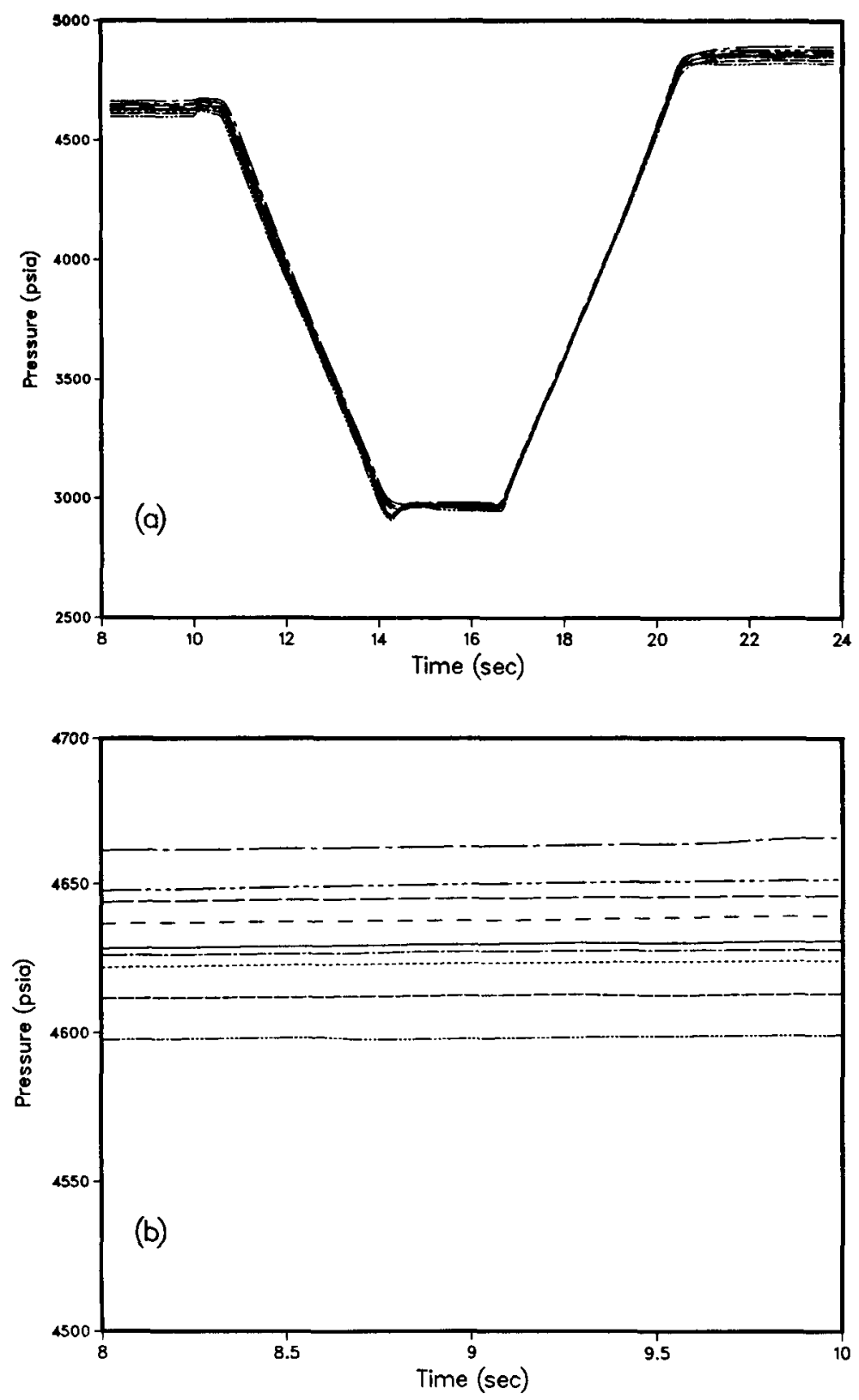

Cose 1

Cose 2

$\operatorname{cose} 3 \ldots$

Cose 4

Cose 5

Cose

Cose 7

Cose 8

Cose $9-1$

Figure 19. $M C C$ coolant discharge pressure response (a). for the entire simulation and (b). at $100 \%$ RPL. 


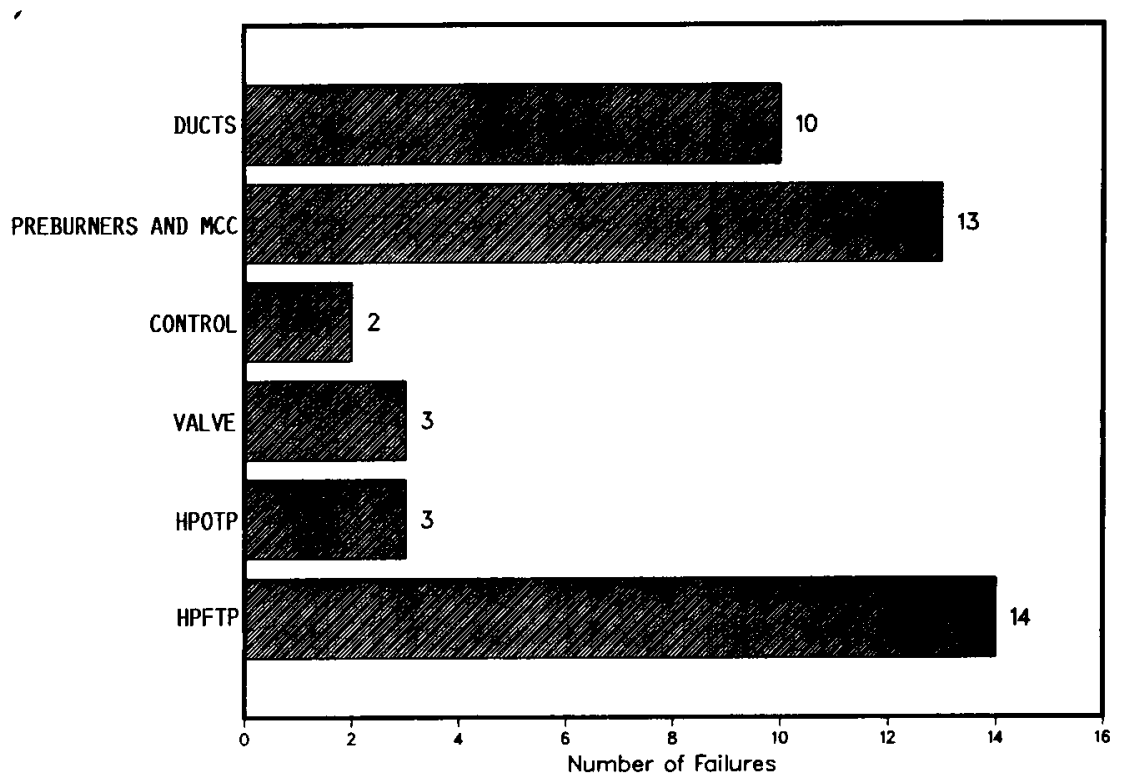

Figure 20. - SSME Test Failures Versus Failed Component.

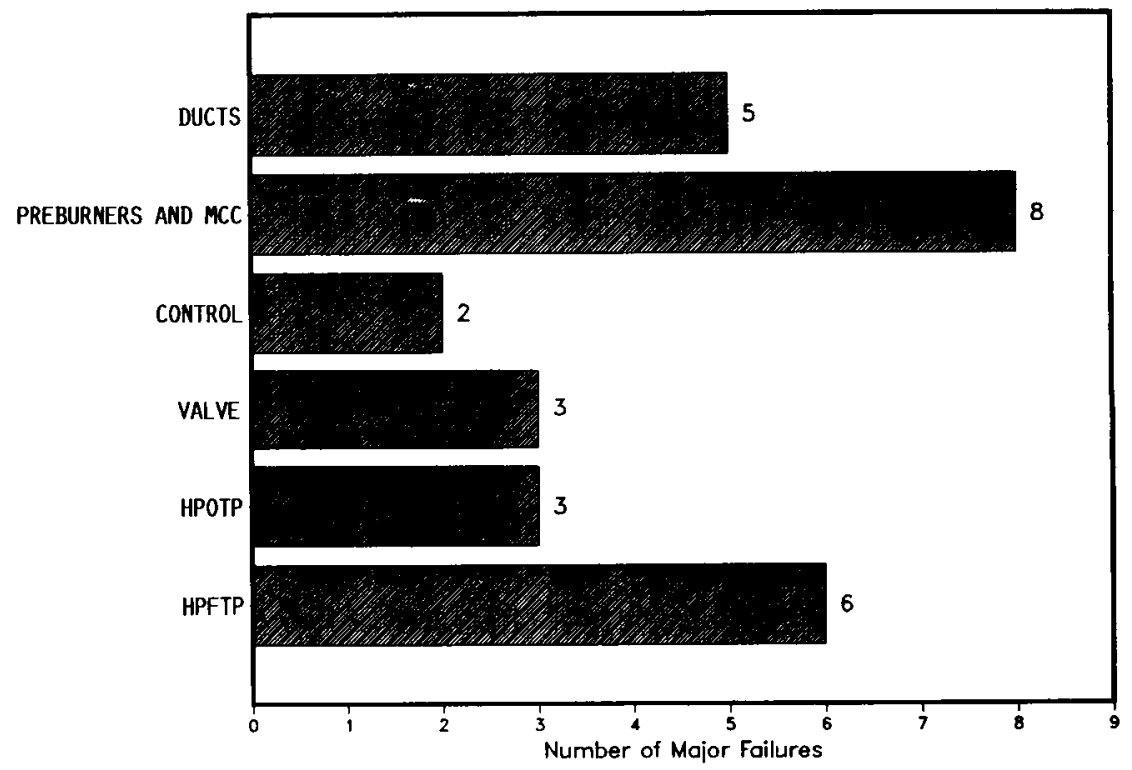

Figure 21. - SSME Major Test Failures Versus Failed Component. 


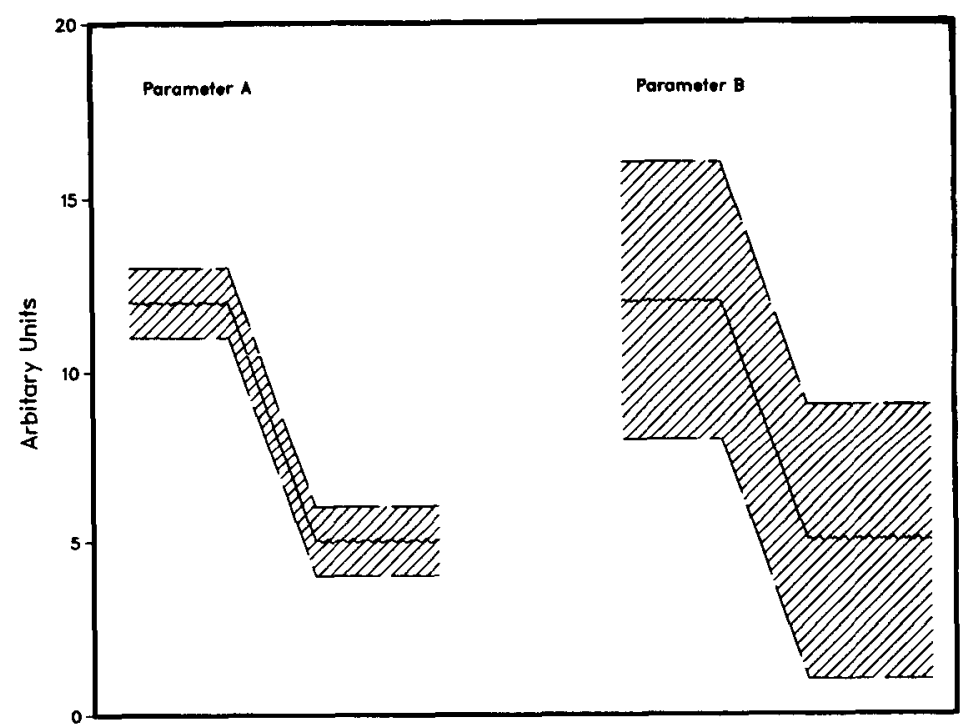

Figure 22. Example response envelopes for arbitrary parameters through the same power level transient. 


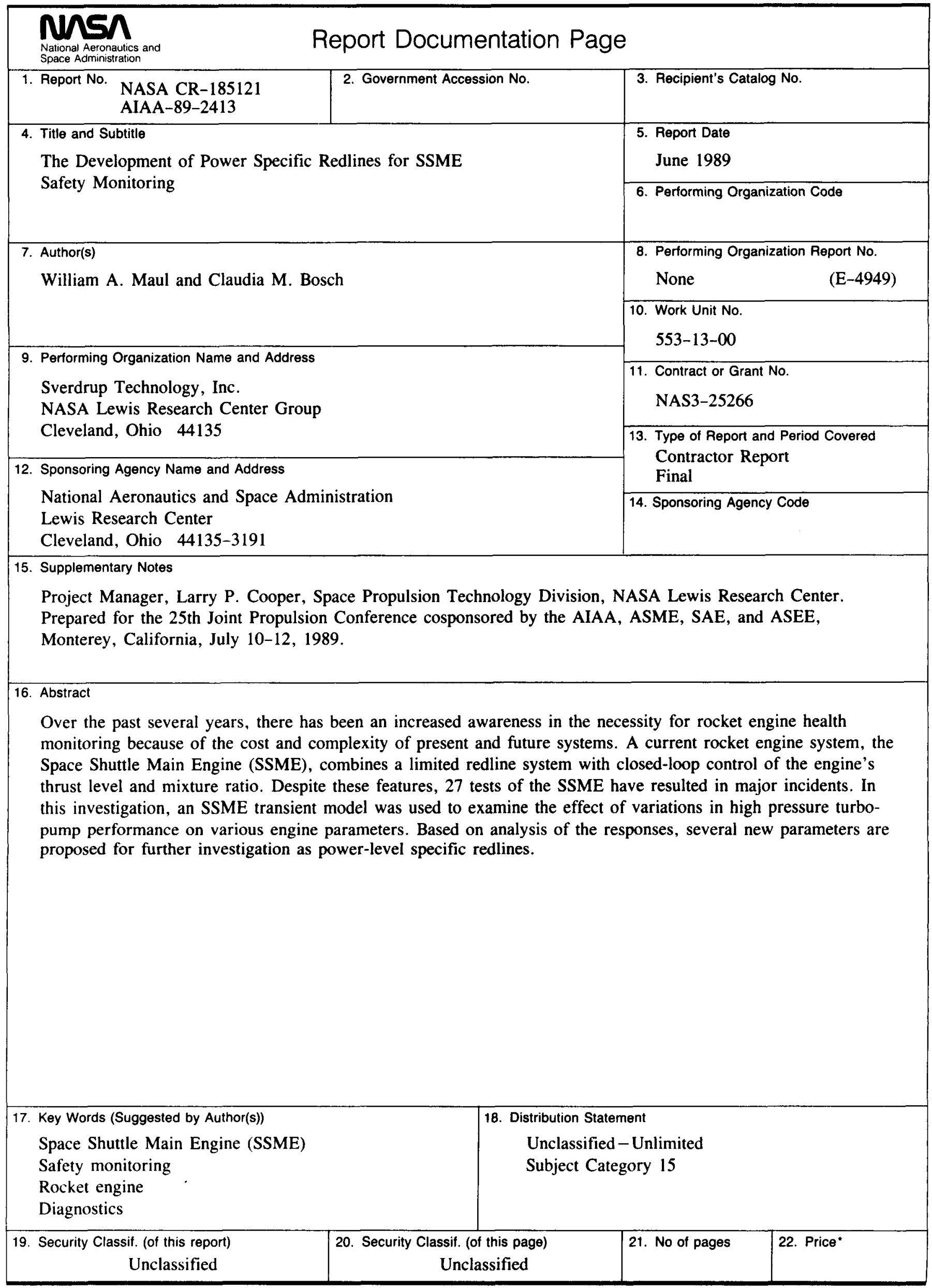

